\title{
COPING WITH EMOTION IN NEW ZEALAND BUSINESS SCHOOLS
}

BY

ALICE MARIA SCAHILL

\author{
A thesis \\ submitted to the Victoria University of Wellington \\ in partial fulfilment of the \\ requirements for the degree of \\ Master of Commerce \\ In Management
}

Victoria University of Wellington

2016 


\begin{abstract}
Emotion is an integral aspect of organisational life and this thesis examines the emotional demands that academics experience in their workplace and the consequences this has for them. At a more specific level, the thesis examines the strategies that academics use to cope with these emotional demands, and how these strategies develop and change over the duration of their career. Using data collected from interviews with academics from business schools across the New Zealand tertiary education sector, findings are presented which demonstrate how academics develop coping strategies and how the organisation provides support. The implications from these findings could have significant effects for organisational practice. Firstly, these findings illustrate that academics experiences emotion in relation to personal, interpersonal, and systemic factors. Secondly, academics adopt a wide array of coping strategies, which have been personally developed by each individual over time. They are not given any organisational training or support for their development of these strategies. In addition, academics use coping strategies both in the workplace and at home in order to attempt to mitigate the negative impacts of the emotional demands of their roles. Finally, academics in their early career lack adequate coping strategies, and appear to have the lowest levels of organisational commitment.
\end{abstract}




\section{Acknowledgements}

I would like to wholeheartedly thank the following people:

Dr. Sarah Proctor-Thomson, for your valuable guidance, advice, and support. After undertaking this research, I have a newfound level of respect and admiration for you and the work that you do. I appreciate every minute that you have spent looking over my work and providing me with thoughtful advice and encouragement.

My parents, Bryan and Robina, who regularly asked for progress updates and continually showed an interest in my work. I love you both and appreciate everything you do for me.

To my classmates, friends and \#DisastersFromMasters; Evie, Cass, Erin and Hamish. Without their camaraderie and support, I would surely have lost my sanity. I thank you all for your constant advice, suggestions, laughs, and beautiful snapchats.

Emma, Peri and Mum, for your willingness to help out with the editing and proof reading of my thesis. I am eternally grateful for the hours you have given up for me.

A final big thank you goes to the research participants who gave up their time to conduct interviews with me. Without your willingness to participate and openness to answer my questions, this research would not have been possible. 


\section{Table of Contents}

COPING WITH EMOTION IN NEW ZEALAND BUSINESS SCHOOLS

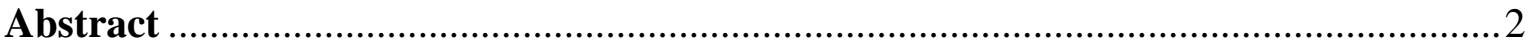

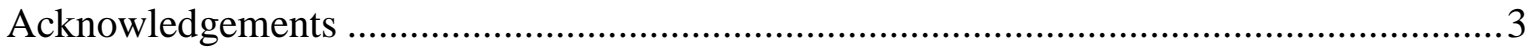

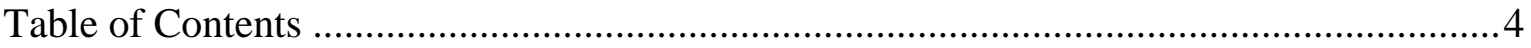

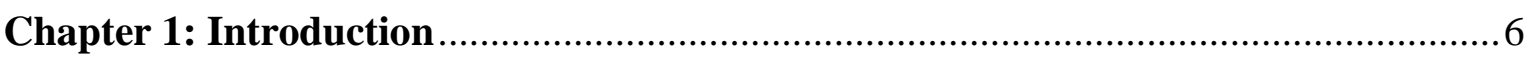

Chapter 2: Emotion in the workplace literature review .............................................

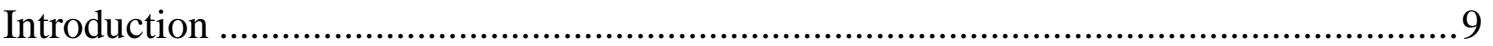

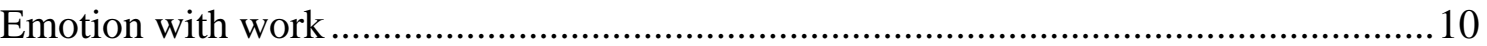

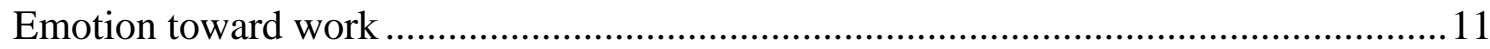

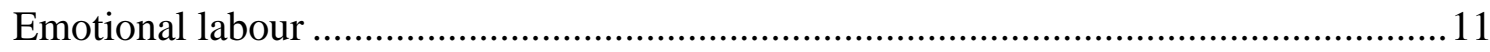

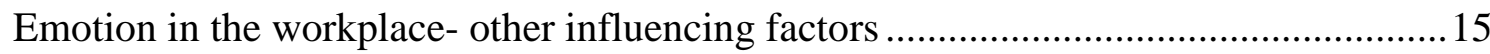

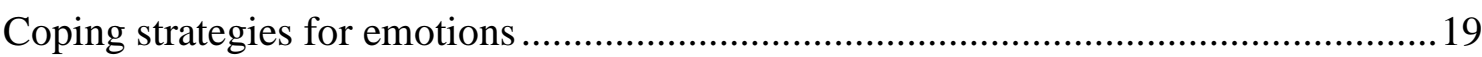

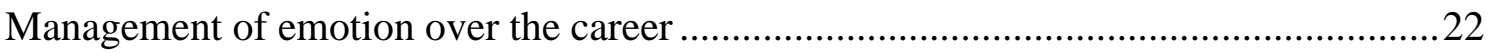

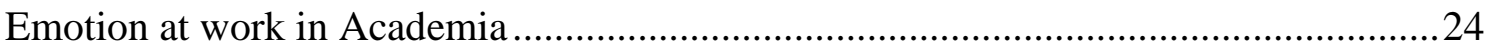

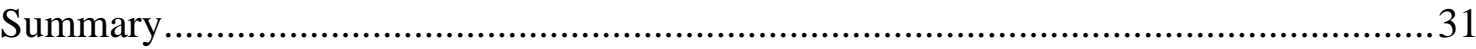

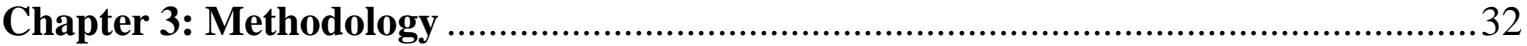

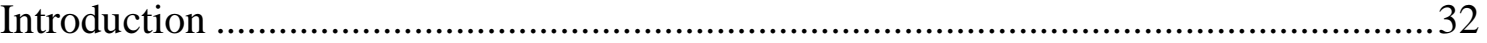

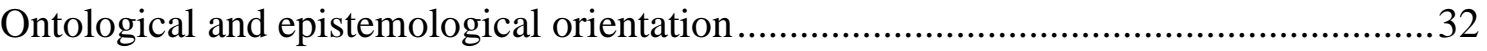

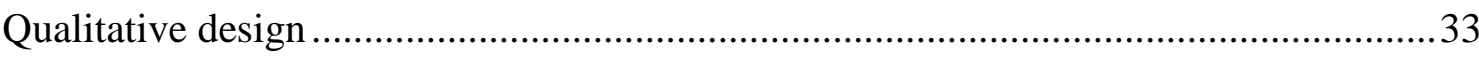

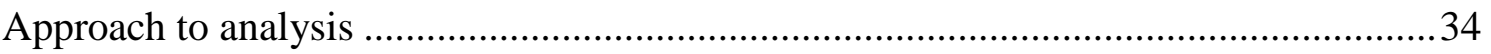

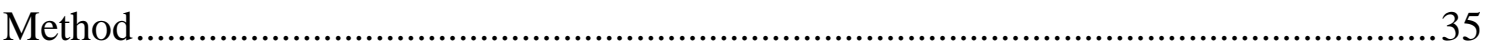

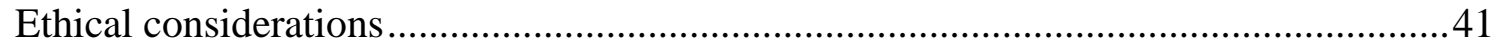

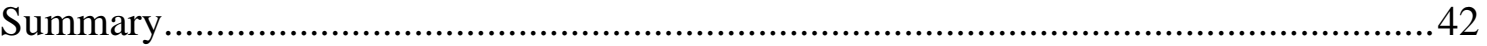

Chapter 4: Causes of Emotion for Academics ........................................................... 43

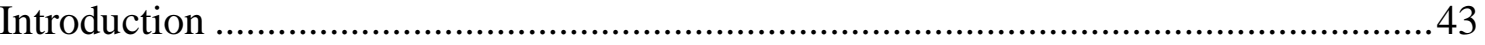

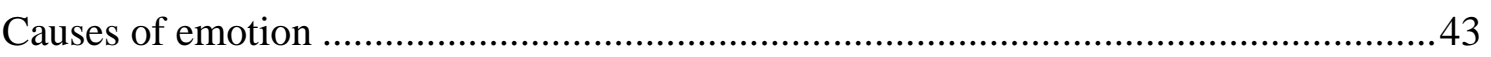

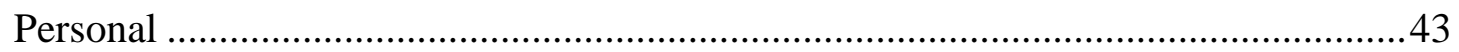

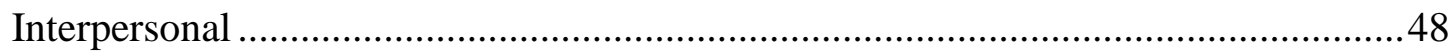

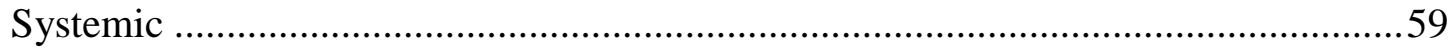

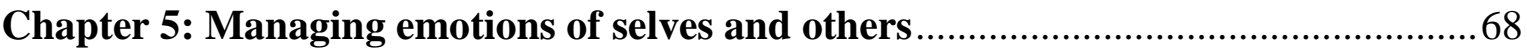

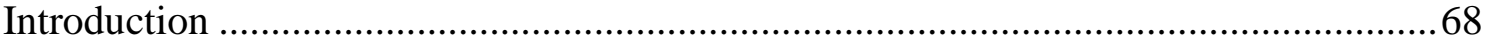

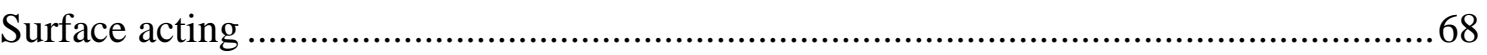

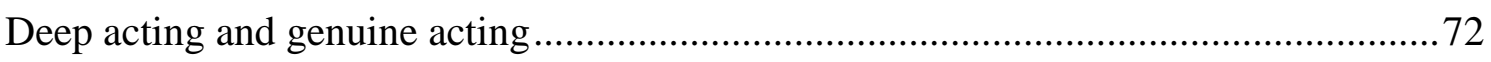

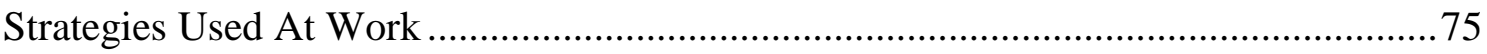




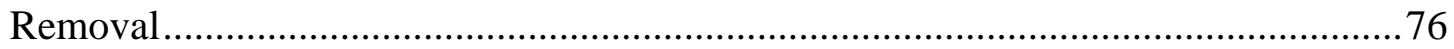

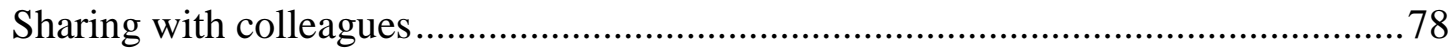

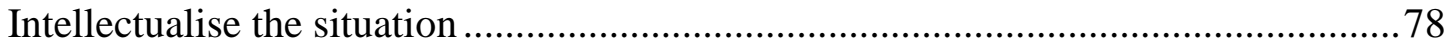

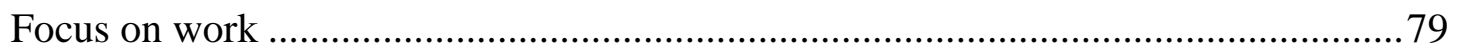

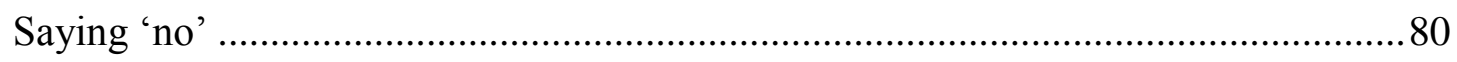

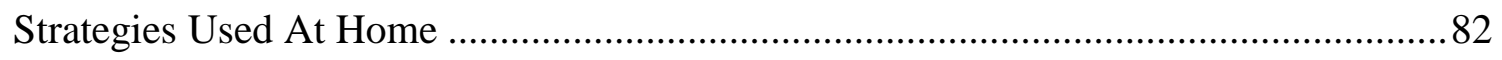

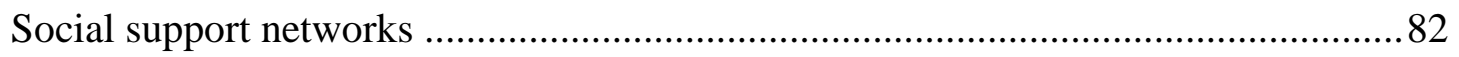

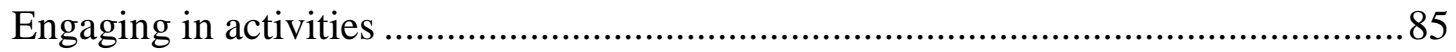

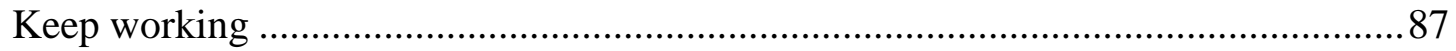

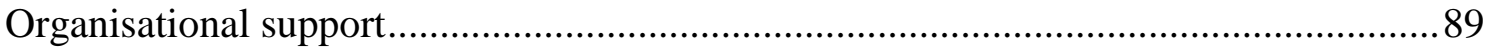

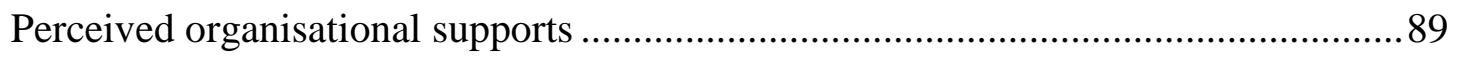

Academic opinions on training for emotion management and coping strategies........90

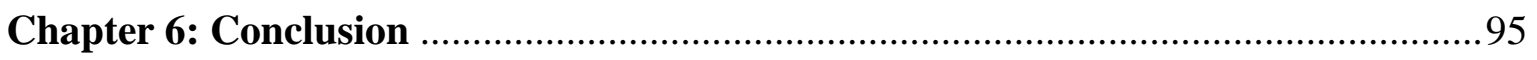

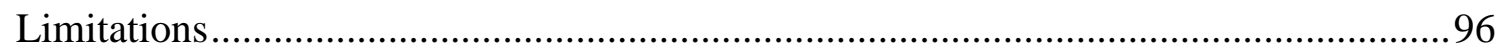

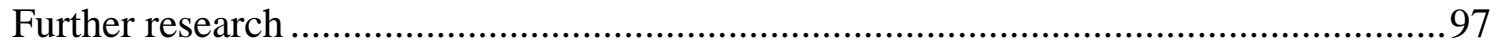

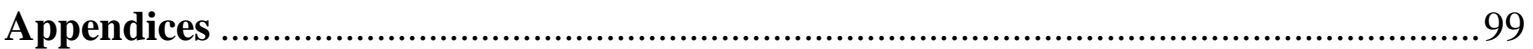

Appendix 1: Research Participant Information Sheet ....................................................99

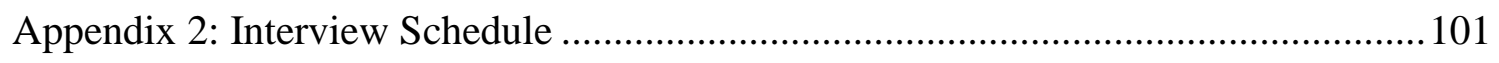

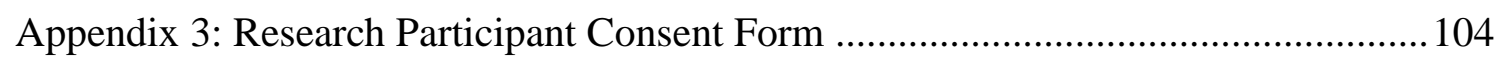

Appendix 4: Research Participant Demographics Form ............................................. 105

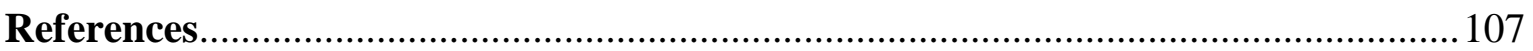




\section{Chapter 1: Introduction}

This thesis presents research on how academics cope with emotion in New Zealand business schools in order to answer the research questions: What are the emotional demands experienced by academics in the workplace and what strategies do they use to cope with these demands? I also seek to answer a secondary research question: How do these strategies develop and change over the duration of their career? Emotion plays an important role in everyday life. I have always been interested in how emotion can be used not only to express yourself but also to communicate with others, to manipulate others, or to change the outcome of any particular situation. Through school, university, and parttime jobs, I have also come to realise that it is not always appropriate to show your true emotions or feelings. There have been many times when I have had to interact with a difficult person and I have felt frustrated or angry. However, more often than not, I keep my cool and appear to be friendly and helpful. These interactions I have experienced and similar ones I have observed and read about have sparked my interest in the study of emotion in the workplace and led to the initial research which has in turn formed the basis of this thesis.

Emotion work has been in sociological and psychological studies for many decades; however it has only come to be studied in organisational behaviour in relatively recent years as researchers realised the importance of effective management of emotion in organisations (Arvey, Renz \& Watson, 1998; Diefendorff \& Gosserand, 2003; Fisher \& Ashkanasy, 2000; Kruml \& Geddes, 2000; Lord, Klimoski \& Kanfer, 2002). There are many unanswered questions regarding emotion in the workplace. In particular, there is limited knowledge about the changing emotional demands of academic work and how employees cope with these. In addition to this, the knowledge surrounding how emotional coping strategies develop and change over the course of a career is sparse. In order to address these gaps this research explores how individuals cope with the emotional demands of their work and how these strategies change over their career duration. It also considers how the organisation acknowledges the emotional demands of their employees and if they provide any support, training, or resources in order to facilitate the development of appropriate coping strategies. The following thesis signifies my contribution by providing answers to these questions. 
In chapter two, the literature review shows that emotion work has been studied frequently in teaching (Jenkins \& Conley, 2005) however, the academic context remains relatively under researched (Constanti \& Gibbs, 2004). As such I began to look into academics as possible participants for this research. As I continued my research into academia, it became clear that the nature of academic work has been changing in relatively recent years, providing a new and interesting base for this research.

Waring (2013) states that "growing market pressures and a commodification of higher education (HE) has had a significant effect on the work of academics, as producers and providers of HE" (p. 397). The academic role has changed significantly and academics are now no longer solely judged on their competencies as scholars but they are also assessed on their abilities to satisfy their customers; the students. Moreover, performance evaluations have changed significantly in many countries including New Zealand and have arguably introduced different elements of emotional demand into academic work. For example, in New Zealand, academics currently have their performance measured periodically via the Performance-based Research Fund, commonly known as, and hence referred to as the PBRF (Tertiary Education Commission, 2016). According to the Tertiary Education Commission (TEC) "The purpose of the Performance-based Research Fund (PBRF) is to ensure that excellent research in the tertiary education sector is encouraged and rewarded. This means assessing the research performance of tertiary education organisations (TEOs) and then funding them on the basis of their performance" (Tertiary Education Commission, 2016). However, in actuality the process of evaluation is individualised in that every active academic involved in research is required to submit an individual portfolio of research publications and is awarded a score. Institutional funding is based on the accumulation of individual scores per capita. This is controversial and has been argued to have introduced significant change to the way academics are managed and their work evaluated (Larner \& Le Heron, 2005). The changing nature of academic work provides a new perspective on academic work and adds to the emotional demands of academics. The academic role has changed significantly and academics are now no longer solely judged on their competencies as scholars but are also assessed on their abilities to satisfy their customers, the students. 
In chapter two, I begin by reviewing existing literature in order to provide the theoretical background for this thesis. This chapter also aims to provide links between emotion in the workplace, career duration and the context of academia. Chapter three outlines the research design for the study. I adopted a social constructionist ontology, which led to the development of a qualitative study with a semi-structured interview approach for data collection. This approach was used in order to best address the gaps, which previous studies have not addressed. Chapters four and five present the findings which emerged from the data collection process in relation to the emotional content of academic work. In these chapters, I relate the findings to extant literature on emotion in the workplace and career duration. I conclude the discussion in Chapter Six and provide the limitations for the study and suggest direction for potential future research.

This study will primarily contribute to current literature on emotion in the workplace by offering insights into how New Zealand academics cope with the emotional demands of their work and if these strategies change over career duration. The goals in order to answer the research questions are threefold. First, it explores the emotional demands faced by academics. Second, it aims to identify strategies used by academics to deal with their emotional demands. Third, it aims to determine if, and how, these coping strategies change over the duration of an academics' career, and finally the research aims to identify how the organisation supports academics with their emotion management. The objectives of this research include the ability to potentially influence managerial practices within the New Zealand tertiary education sector regarding the knowledge and training surrounding coping with emotional labour. This research may also be of interest to academics themselves to reflect on their own experiences in the context of their peers. 


\section{Chapter 2: Emotion in the workplace literature review}

\section{Introduction}

The study of emotion in the workplace is not new; scholars have been studying the role of emotions in organisations and the emotional lives of employees for the past 40 years (Miller, 2002). One of the first widely acknowledged studies of emotion in organisations was by Arlie Hochschild (1983) who studied emotion in the work of flight attendants. Since then research has proliferated and a number of different types of emotional content, demands and behaviours in the workplace have been categorised. Drawing from a conceptual framework of workplace emotion developed by Miller, Considine and Garner (2007), this chapter reviews the vast literature as it pertains to:

- 'emotion with work' (Emotion stemming from interaction with co-workers),

- 'emotion toward work' (Emotions in which work is the target of the feeling), and

- 'emotional labour' (Inauthentic and authentic emotion expressed in interaction with others in order to produce the appropriate state of mind in others. It can involve surface acting, deep acting and/or genuine acting)

(Miller et al., 2007, p. 231; see also Hochschild, 1983; Ashforth \& Humphrey, 1993) ${ }^{1}$.

In addition, throughout the thesis the term 'emotion work' is used as an all-encompassing term that subsumes these three concepts and refers to the activities and behaviours involved in responding to the emotional content of work generally. The types of "emotion work' above can occur independently of each other however; they are also intrinsically linked and can occur simultaneously.

This conceptual section is then followed by an overview of the outcomes and consequences of emotion work and then the coping strategies individuals use to deal with

\footnotetext{
${ }^{1}$ Miller et al's. (2007) framework referred to five conceptual areas rather than three. In addition to those outlined in Table 1, Miller et al. (2007) identified emotion at work (emotion from non-work sources experienced in the workplace) and emotional work (authentic emotion in interaction with customers and clients) as important aspects. In this study the concept of emotion at work will not be examined as the focus this research only considers emotion caused by factors within the organisation. Emotional work will not be examined as this concept fits under the definition of genuine acting; one of the components of emotional labour.
} 
these. A discussion of career duration in relation to emotion work then follows. This chapter then concludes with an overview of emotion work for academics and provides the context for the current academic workplace.

\section{Emotion with work}

Emotion with work is the emotion caused by relationships and interactions specifically with co-workers and managers. This can be one of the strongest sources of emotion in the workplace and again can induce both positive and negative emotion (Miller et al., 2007). One of the basic forms of emotion with work is simply organisational relationships. Good organisational relationships consist of certain levels of trust and respect and can create positive emotions. When organisational relationships do not have these components, they can cause negative emotions, particularly towards managers or supervisors as they are in a position of authority. In Miller et al's (2007) work, when employees felt that their superiors had trust and respect for them, then the feeling was more likely to be reciprocal. Waldron (2000) also noted that relationships with colleagues can have a strong influence on an individual's emotions, serving to enhance, intensify, diminish or eliminate particular emotions. For example, an individual may be feeling sad about a particular situation, and a conversation with a colleague may help them to see that they should not feel sad. A single conversation with a supportive colleague could have a positive influence on their emotional outcome.

Interactions are another important component of emotion with work. Positive emotions arise from colleagues who support each other in the workplace. Ray (1987) showed that many employees relied on their colleagues for emotional support rather than their family or friends outside of work, as their colleagues were the only people who truly understood what they are feeling. As well as emotional support, interactions with colleagues can involve sharing humour, complaining or venting, and emotional abuse (Waldron, 2000). An example of emotional abuse is when employees in positions of power target abuse at less powerful employees. It has been shown that as a result of abuse, employees can be muted as they experience repeated mistreatment (Meares, Oetzel, Torres, Derkacs \& Ginossar, 2004).

A key component of emotion with work, results from the employees' own perspectives of their colleagues. The actions of a colleague could be viewed as wrong in the eyes of the 
employee, which, in turn, could invoke negative emotions. Each individual has their own ethical standards or moral code and if they believe that somebody else is not carrying out their duties in the 'right' way then this would cause negative emotions and ill-feelings towards that particular colleague (Miller et al., 2007). These are essentially people that they viewed as "unethical, dishonest, or unable to pull their weight on the job (Miller et al., 2007, p. 250).

\section{Emotion toward work}

With emotion toward work "the object of the emotion is the work or the workplace" (Miller et al., 2007, p. 238). Emotion toward work has historically been referred to simply as job satisfaction however; emotions about individuals' work can be examined in more detail (Miller et al., 2007). Emotion toward work can be both positive and negative and can vary over time. Motivation factors tend to be the aspects of work that elicit positive emotions from employees. These are factors such as achievement, recognition, responsibility, or challenging work. These factors allow employees to find meaning in their work, grow their self-esteem, and enhance their personal growth (Miller et al., 2007). Other factors such as working conditions, salary, job perks and company policies all serve to help keep employees happy as well (Herzberg, 1976; Herzberg, Mausner, \& Snyder, 1959). In contrast, negative emotions are caused by factors such as workload, role conflict and role ambiguity (Miller, Ellis, Zook \& Lyles, 1990). Some authors argue that emotion toward work occurs simply in relation to the fit between the characteristics of the job and the individual (Holland, 1973; Stern, 1970). This fit between the individual and the job can be in relation to skills or personality traits (Miller et al., 2007).

\section{Emotional labour}

Arlie Hochschild's (1983), early work defined emotional labour by examining how it is used by flight attendants. She described emotional labour as "the labour that requires one to induce or supress feeling in order to sustain the outward countenance that produces the proper state of mind in others" (Hochschild, 1983, p. 7). Essentially it is the regulation of emotions as required by a particular work role. Three components of emotional labour were developed by Hochschild (1983) relating to the interactions of the emotional labourer with others. The first component is that emotional labour involves face-to-face or voice-tovoice interactions with other people. The second is that workers use their emotions to influence the emotions of others. Finally, organisations have display rules and 
requirements which shape the emotions of employees and these may or may not be formalised in job descriptions, staff training, and the company mission statement or embedded in the organisational culture. The third component is critical to the concept of emotional management, as within most jobs, individuals are expected to manage their emotions while at work. However, in jobs where customer service is vital, then the management of the individuals' emotions is dictated or directed and this is where emotional labour is separated from emotional display (Hochschild, 1983). Hochschild's study found that the performance of emotional labour can have negative impacts on employees and often resulted in stress, burnout, and self-estrangement. Since this study, emotional labour and emotion in the workplace has been studied and the concepts developed by many others.

Morris and Feldman (1996) defined emotional labour as "the effort, planning, and control needed to express the organizationally desired emotion during interpersonal transactions" (p. 987). They conceptualise emotional labour as having four dimensions: "frequency of appropriate emotional display, attentiveness to required display rules, variety of emotions to be displayed, and emotional dissonance generated by having to express organizationally desired emotions not genuinely felt" (Morris \& Feldman, 1996, p. 986). They then examine the antecedents of emotional labour in depth and note that antecedents of emotional labour can be both organisational factors and individual variables.

Grandey (2000) states that emotional labour is influenced in part by the situational settings in which the employee is located and that emotional regulation is more likely to occur for those employees with extended customer interactions. She also found that while good organizational performance may be influenced by emotional labour, it can be detrimental to an employees' health (Grandey, 2000). Similar to findings by Morris and Feldman (1996), it was also found that both personal and organisational characteristics can influence the performance of emotional labour (Grandey, 2000).

\section{The components of emotional labour}

\section{Surface acting \& deep acting}

Emotion theorists have proposed that emotions consist of several subsystems (Scherer, 1997), for example; "subjective feeling, physiological reaction patterns and expressive 
behaviour, the latter including facial expression, voice, and gesture" (Zapf, 2002, p. 243). Aligning with this, Hochschild (1983) developed the concepts of surface acting and deep acting; "the effort or act of trying to display the appropriate emotions, not to the outcomes" (Ashforth \& Humphrey, 1993, p. 93). Table 1 presents the key components of emotional labour, which are important for this research.

Surface acting is when an individual manages their expressions and behaviour as opposed to their feelings (Hochschild, 1983). This does not mean that the actor does not feel emotion; rather it means that their displayed emotion is different to their felt emotion (Ashforth \& Humphrey, 1993). Deep acting however, is when the individual attempts to genuinely experience the emotion that they are outwardly displaying (Hochschild, 1983). In this case, inner feelings are regulated (Zapf, 2002) and the emotions and behaviours that are outwardly expressed are an indirect effect (Ashforth \& Humphrey, 1993). There are two ways in which an individual can actively induce, suppress, or shape deep acting. The first is exhorting feeling, where an individual consciously attempts to suppress or evoke a particular emotion. The second is trained imagination, where the individual thinks of a particular image or memory that they know will induce the desired emotion (Hochschild, 1983).

\section{Genuine acting}

Ashforth and Humphrey (1993) identified that genuine acting should be classed as a new category of emotional labour and this is when employees are able to express the appropriate emotions naturally. They developed this concept as Hochschild's definition of emotional labour assumed that in order to perform emotional labour individuals must be either surface acting or deep acting but fails to acknowledge that individuals can genuinely feel and perform the organisationally appropriate emotions which therefore requires no 'acting'. Tracy and Tracy (1998) and Karabanow (1999) show that genuine acting can involve both positive and negative feelings such as sadness, irritation, anxiety, disgust, pleasure, and amusement which can arise when interacting with other people. For example, an employee can feel sad or sympathetic toward a client or colleague or an employee can feel pleasure after interacting with a client. 


\section{Deliberate dissonance acting}

A final type of acting has since been identified as deliberate dissonance acting (DDA), which is the suppression of emotions or deliberate acting in order to achieve specific work goals (Van Gelderen, Bakker, Konijn, \& Binnewies, 2014; Zapf, 2002). However, this form of emotional management is performed "without the organizational requirement to actually display or feel these emotions" (Van Gelderen et al, 2014, p. 886). It is similar theoretically to surface acting; however, DDA is more conscious and proactive whereas surface acting can be performed as a routine process without any conscious thought (Van Gelderen et al., 2014). Zapf (2002) notes that DDA is unique as the acting is done in a deliberate and conscious manner in order to achieve work goals, however, there are no organisational requirements for the employee to display these emotions.

\section{Feeling rules and Display rules}

Hochschild (1983) also developed the concept of 'feeling rules', which "define what we should feel in various circumstances" (Hochschild, 1979, p. 289). This term is important to Hochschild's work on emotional labour in which she focuses strongly on the management of internal feelings. Hochschild (1983) describes feelings as a "form of pre-action" (p. 56) which makes them "powerful tools for direction action" (p. 56). Therefore, feeling rules guide emotion work and more specifically emotional labour, through the establishment of a sense of "obligation that governs emotional exchanges" (Hochschild, 1983, p. 56). Our feeling rules can be influenced by different social groups and social groups can also have special ways of recognising these feeling rules and giving rule reminders (Hochschild, 1983).

'Feeling rules' differ from 'display rules' which are the norms about the emotions that should be expressed and they are "generally a function of societal norms, occupational norms, and organizational norms" (Ashforth \& Humphrey, 1993, p. 91; Rafaeli \& Sutton, 1989). Goffman (1959) was the first to suggest that people always follow some rules when interacting in social situations. Ekman (1973) then developed this idea into the concept of display rules where he defined them as the norms or standards of behaviour, which indicate the appropriate emotions for the situation and how they should be expressed. Both of these examples however were not concerned with work-based emotion and how people interact at work; rather they examined how people interact in general. Ashforth and Humphrey (1993) focus on display rules as they emphasise the outward expressions used 
in emotional labour as opposed to the management of internal feelings. It is important to note that some organisations may make display rules explicit, but feelings rules are typically implicit (Briner, 1995, 1999; Zapf, 2002).

Using the concept of display rules developed by Ekman, (1973) and further developed by Rafaeli and Sutton, (1989), a new perspective on emotional labour was developed by Ashforth and Humphrey (1993). Display rules are defined as the "norms about which emotions members of a social system ought to express" (Rafaeli \& Sutton, 1989, p. 8). These differ from Hochschild's 'feeling rules' which "define what we should feel in various circumstances" (Hochschild, 1979, p. 289). Ashforth and Humphrey (1993) agree with Hochschild (1983) that emotional labour can have negative effects; however, they also noted that emotional labour can have positive effectives such as task effectiveness and self-expression. Task performance is improved when the audience to the emotional labour perceives the performance as sincere. Emotional labour also helps employees to regulate interactions with customers, which in turn leads to employees believing in their abilities to fulfil their job requirements thus increasing their task effectiveness (Ashforth \& Humphrey, 1993). Self-expression is facilitated through the performance of emotional labour as display rules allow the employee to "project at least some of their 'authentic self' into the enactment" (Ashforth \& Humphrey, 1993, p. 95). This ability to personalise emotional labour performances is also linked with satisfaction and well-being (Ashforth \& Humphrey, 1993; Sundstrom, 1986).

\section{Emotion in the workplace- other influencing factors}

There are several other factors, which can influence emotional labour and other emotion work within the organisation. These include personal and organisational characteristics. Following social identity theory, Ashforth and Humphrey (1993) argue that 'identity' is an important factor in emotional labour. Social identity theory states that a person is comprised of a personal identity and a social identity. Their personal identity is made up of idiosyncratic characteristics such as their traits, abilities, and skills while their social identity is made up of salient group classifications such as their religious affiliations or organisational roles (Ashforth \& Mael, 1989; Tajfel \& Turner, 1985). When an individual identifies with a particular group, they begin to take on the characteristics of the group and "develop a sense of who they are, what their values, goals and beliefs are, and what they ought to do" (Ashforth \& Humphrey, 1993, p. 98). They state that as a person identifies 
more with a particular role then they "feel most authentic" (Ashforth \& Humphrey, 1993, p. 98), can have the ability to moderate some of the negative effects of emotional labour and perform the emotional labour more easily.

Hochschild (1983) also argued that personal variables such as gender, age, and experience can also play an important role in emotion work and emotional labour. Historically, Western culture has encouraged men to repress their emotions while women are expected to display them (Chodorow, 1980); however this may change as women enter masculinised workspaces. It has also been shown that women tend to identify and interpret emotional cues and expressions of others (Domagalski, 1999). Others have also argued that due to gendered expectations regarding emotion work, women and men may be rewarded differently for their emotional display (for example, Adkins, 1995). Hochschild (1983) identified that as employees increased in age they have more emotional experiences in which they can draw from in order to better control their emotions and engage in emotional labour.

Experience is also another key variable identified by Hochschild (1983), as being important in emotion work. She states employees in a new role, with less experience or occupational tenure are more likely to feel uncertainty in their role. This raises questions about how the ability of individuals to engage in emotional management of themselves and others changes over the course of a career. This will be discussed further below. 


\begin{tabular}{|c|l|}
\hline \multicolumn{2}{|l|}{ Table 1: Concept definitions related to the management of emotion in selves and others } \\
\hline Key Terms & \multicolumn{1}{|c|}{ The Concept } \\
\hline Surface Acting & $\begin{array}{l}\text { Simulating emotions that are not actually felt, which is } \\
\text { accomplished by careful presentation of verbal and nonverbal cues, } \\
\text { such as facial expression, gestures, and voice tone. (Ashforth \& } \\
\text { Humphrey, 1993,p. 92) }\end{array}$ \\
\hline Deep Acting & $\begin{array}{l}\text { Whereby one attempts to actually experience or feel the emotions } \\
\text { that one wishes to display. (Ashforth \& Humphrey, 1993, p. 93) }\end{array}$ \\
\hline Genuine Acting & $\begin{array}{l}\text { Instances whereby one spontaneously and genuinely experiences } \\
\text { and expresses the expected emotion. (Ashforth \& Humphrey, 1993, } \\
\text { p. 94) }\end{array}$ \\
\hline Deliberate Dissonance Acting & $\begin{array}{l}\text { Emotional display results from strategic behaviour and there is } \\
\text { neither an intention nor a requirement from the organization to 'feel' } \\
\text { the displayed emotions. (Zapf, 2002, p. 247) }\end{array}$ \\
\hline Feeling Rules & $\begin{array}{l}\text { Guide emotion work by establishing the sense of entitlement or } \\
\text { obligation that governs emotional exchanges. (Hochschild, 1983, p. } \\
56)\end{array}$ \\
\hline Display Rules & $\begin{array}{l}\text { Norms about which emotions members of a social system ought to } \\
\text { express. (Rafaeli \& Sutton, 1989, p. 8) }\end{array}$ \\
\hline
\end{tabular}

\section{Outcomes}

As shown in the previous section of the chapter, there are many aspects to emotion work in organisations. All of these aspects can have significant consequences for both the employee and the employer. For example, early studies of emotion work emphasise the harmful effects it can have on workers, although literature shows that there can be both positive and negative outcomes resulting from the performance of emotional labour (Pugliesi, 1999). It has also been shown that both the frequency and intensity of emotion work will influence the intensity of the outcomes for the actor (Hochschild, 1983; Morris $\&$ Feldman, 1996; Zapf, 2002). The form of emotion work can also influence the outcomes for the employee (Pugliesi, 1999). While emotional labour may have negative impacts on the employee, its enactment is generally beneficial to the organisation (Grandey, 2000). The organisation or occupation can also impact on the outcomes of emotional labour. 


\section{Negative consequences}

It has been found that engaging in emotional labour can often result in negative effects on employees such as absenteeism, depression, substance abuse, diminished self-esteem, and burnout (Grandey, 2000; Hochschild, 1983; Pugliesi, 1999; Rafaeli, 1989; Zapf, 2002). Hochschild (1983) also found that the extensive emotional labour that is required in some jobs can result in self-estrangement, alienation or exhaustion. Gimlin (1996) found that emotion work undermines the worker's sense of professionalism, while others have found that it undermines job satisfaction (Bulan, Erickson \& Wharton, 1997; Parkinson, 1991; Pugliesi \& Shook, 1997). Other negative consequences associated with the performance of emotional labour and emotion work include dissatisfaction, separation of self and true feelings (Hochschild, 1983), lack of empathy and feeling robotic (Albrechet \& Zemke, 1985), lack of work identity (Van Maanen \& Kunda, 1989), and a lack of openness (Kahn, 1990).

Emotional dissonance "occurs when an employee is required to express emotions which are not genuinely felt in the particular situation" (Zapf, 2002, p. 245). Simply put, "as a consequence of 'acting emotions', the employee may experience a state of discrepancy between felt and displayed emotions" (Van Gelderen et al., 2014, p. 886). Both surface acting and DDA can result in emotional dissonance and most studies on emotion work include this concept (for example Abraham, 1998; Adelmann, 1995; Ashforth \& Humphrey, 1993; Brotheridge \& Lee, 1998; Büssing \& Glaser, 1999; Grandey, 1998; Kruml \& Geddes, 1998; Mann, 1999; Morris \& Feldman, 1996, 1997; Nerdinger \& Röper, 1999). Emotional dissonance has been shown to have negative consequences on employee well-being (Bakker \& Heuven, 2006; Zapf, 2002). Morris and Feldman (1996) examined the consequences of emotional labour performances and show that the majority of low job satisfaction is a result of emotional dissonance.

\section{Positive consequences}

Although most studies focus on the negative outcomes of emotion work, it has also been acknowledged that it can be positive for the employee depending on how it is enacted (Grandey, 2000; Hochschild, 1983; Kruml \& Geddes, 2000; Pugliesi, 1999). When emotion work is "experienced as self-enhancing or when workers are in control of their emotion management" (Pugliesi, 1999, p. 130) then it appears to have positive consequences. It has been found that workers have reported higher levels of job 
satisfaction in jobs that require higher levels of emotional labour (Wharton, 1993, 1996; Adelmann, 1995). Emotional labour can also be empowering for the worker when they are managing the emotions of others (Leidner, 1993; Stenross \& Kleinman, 1989; Tolich, 1993). Greater job autonomy has also shown to diminish the effects of emotion work for employees (Wharton, 1993, 1996).

\section{Coping strategies for emotions}

As shown in the previous section, the consequences of emotion work are varied and can have significant impacts for the employee and the organisation. In order to try to mitigate the negative consequences, employees adopt coping strategies. The coping strategies are used by employees in an attempt to "protect their own psychological and emotional wellbeing" (Hammonds \& Cadge, 2014, p. 166) and these will be discussed in this section of the literature review.

The literature on coping strategies is currently underdeveloped and there are only a few articles, which address the topic specifically in regards to emotion work. The earliest research looks at emotional labour and gender in police and reviewed coping mechanisms for emotion regulation (Martin, 1999). Bailey and McCollough (2000) then examined emotional labour coping strategies for service agents and the consequences that these could have at an organisational level. More recently, strategies for coping with the emotional demands of their work have been examined in relation to nursing (Hammonds \& Cage, 2014) and paramedics (Williams, 2013). A wide variety of strategies have been identified that employees use to cope with their emotion work. Some of these strategies occur on the job while others occur off the job and only a limited number of strategies are supported by the organisation (Bailey \& McCollough, 2000; Hammonds \& Cadge, 2014; Martin, 1999; Williams, 2013). It has been identified in a number of studies, that organisations should be acknowledging the importance of recognising emotion work, and that they should be actively aiming to train their staff in developing adequate coping strategies (Hammonds \& Cage, 2014). Due to the negative outcomes for the enactment of emotion work, particularly emotional labour, it has been shown that it is important for organisations to recognise this, because the negative outcomes for employees such as burnout, often result in negative outcomes for the organisation such as lower levels of job commitment (Sawbridge \& Hewison, 2013). 
Folkman and Lazarus (1980) explain that people use either emotion-focused or problemfocused coping strategies as forms of emotion management in dealing with stress or stressful situations. Emotion-focused strategies are "cognitive and behavioural efforts directed at reducing or managing emotional distress" (Folkman \& Lazarus, 1980, p. 225), and can include withdrawal (Mobley, Griffeth, Hand, \& Meglino, 1979), self-blame, wishful thinking (Vitaliano, Russo, Carr, Maiuro, \& Becker, 1985), and avoidance (Lazarus, 1979). Problem-focused strategies are "cognitive problem-solving efforts and behavioural strategies for altering or managing the source of the problem" (Folkman \& Lazarus, 1980, p. 224). Their study found that age had no effect on the type of coping strategy used and they found no gender differences in emotion-focused coping strategies however, they found that men used more problem-focused coping strategies than women (Folkman \& Lazarus, 1980).

\section{Coping strategies on the job}

There is a variety of coping strategies that are used by employees in various sectors to deal with their emotional demands while they are working. The dominant strategies are venting or sharing their emotions with colleagues (Bailey \& McCollough, 2000; Hammonds \& Cadge, 2014; Martin, 1999; Williams, 2013), and humour (Martin, 1999; Williams, 2013). Venting and sharing emotions with colleagues was used by employees because they were seen to have a shared understanding of what the employee were going through and could relate to or help to change their perception (Hammonds \& Cadge, 2014). This strategy also helped to build rapport with each other and build relationships. Williams (2013) identified that while the paramedics in her study had the provision of formal counselling within their organisation, many respondents preferred talking to their colleagues instead as they had personal insights and understandings of the issues. Although the respondents did not prefer to talk to a counsellor, they did have a support mentor and many respondents valued talking through their job with their mentor (Williams, 2013). The provision of a mentor helped to build confidence, provide reassurance, and increase job satisfaction. Humour is used as a coping strategy as it could be used to lessen the harshness or impact of a particular event and relieve tension (Martin, 1999). Humour also allows an event to be translated into a group experience and reinforce the solidarity of the group (Martin, 1999). Williams (2013) explained that respondents saw humour as a positive coping strategy used to deal with difficult situations and to move on from them quicker. It was also used to 
"facilitate camaraderie, catharsis, and reduce stress and was crucial in the maintenance of 'sentimental order'” (Williams, 2013, p. 211).

Other strategies identified as ways of coping with the emotional demands of work include: organisational rituals, reframing situations, compensation, punishment, expediting, avoidance, discourteousness, and referral, (Bailey \& McCollough, 2000; Hammonds \& Cadge, 2014; Martin, 1999; Williams, 2013). Organisational rituals, such as a ceremony related to the death of a police officer, are used as a way of facilitating collective coping for tragic or stressful events (Martin, 1999) and also provide a time where the "rules of emotional reserve are suspended" (Martin, 1999, p. 123). Reframing situations occurs when an employee will change the focus on a particular event to highlight the positives as opposed to the negatives. For example, a nurse might reframe the death of a patient to emphasise and focus on the work the nurse did to help the patient and their family rather than the death itself (Hammonds \& Cadge, 2014). Compensation, punishment, expediting, avoidance, discourteousness, and referral were other coping strategies used in a variety of combinations by service agents (Bailey \& McCollough, 2000). In Bailey and McCollough's (2000) research of service agent's compensation and punishment occurred when the employee would either try to be especially nice to customers to compensate for negative emotions or they would not try to be nice at all to especially difficult customers, sometimes even ignoring them completely. Expediting occurred as the employee would attempt to get the transaction with the customer over as quickly as possible in order to end the unpleasant situation, while avoidance would occur as the employee would remove themselves from the unpleasant situation. Discourteousness was similar to punishment however, it occurred as the employee tried to be nice and manage their emotions but did not succeed and so became discourteous to the customer. Finally, referral would occur as a last resort when other coping strategies had failed. It involved referring the customer to the manager or another staff member in order to remove themselves from the negative situation while still allowing the customer to be dealt with.

\section{Coping strategies off the job}

There are also a variety of coping strategies that are used by employees in various sectors to deal with their emotional labour when they are finished working for the day or week and they are away from "the norms of their workplaces and the supports for emotion management present in them" (Hammonds \& Cadge, 2014, p. 163). These strategies are 
used because often the emotional demands of their work will still be having an effect on the employee even though they are not at work. Strategies included socialisation, drinking, partaking in activities, venting or sharing information with family and/or friends and ‘calling-in' (Hammonds \& Cadge, 2014; Martin, 1999; Williams, 2013). Socialising with fellow workers outside of the workplace has been found to be an important way to discharge tension, relieve stress and also "promote feelings of group unity, trust and camaraderie" (Martin, 1999, p. 123). Socialisation often includes drinking together (Hammonds \& Cadge, 2014; Martin, 1999), or participating in athletic activities and for some policemen, sexual escapades (Martin, 1999). Socialisation, venting, sharing information about their work and partaking in activities with other friends and family has also been identified as important in helping employees to cope (Hammonds \& Cadge, 2014; Williams, 2013). Other activities include; exercising, watching television, listening to music, praying, attending a sports game, or even crying. These are used to take employees minds away from the emotional strains of their work and "create and maintain emotional boundaries (Hammonds \& Cadge, 2014, p. 168).

\section{Management of emotion over the career}

As noted earlier in the literature review, Hochschild (1983) identified that experience is important in emotion work. She states employees in a new role, with less experience or occupational tenure, are more likely to feel uncertainty in their role. A key aspect of career duration is experience and emotion.

Within any working life and in any occupation, people go through "typical evolutionary phases called career stages" (Kaur \& Sandhu, 2010, p. 143; Super, 1957). Each career stage is characterised by activities and psychological factors in the individuals working life, no matter what their background is or the occupation they are in (Arthur, Hall, \& Lawrence, 1989; Levinson, 1986; Levinson, Darrow, Klein, Levinson, \& Mckee, 1978; Ornstein, Cron, \& Slocum 1989). Levinson et al. (1978) states that individuals will go through "some kind of personal or career related decisions" (p. 143) every five to seven years. As people move through each stage of their career it is likely that their attitudes, expectations and goals will change and this has important managerial implications (McElroy, Morrow \& Wardlow, 1999). 
Career stages have been categorised in various ways by many authors, often based on chronological age (Kaur \& Sandhu, 2010). This is due to the behaviours and attitudes of individuals changing as they age and are influenced by their personal experiences, and their experiences of the environment (Beck \& Wilson, 2001). Super (1957) states that there are three stages in an individual's career. These are exploration, establishment, and maintenance and are based on "the qualitatively different psychological task of each stage (Kaur \& Sandhu, 2010, p. 143). Brooks and Seers (1991) consider five career stages based purely on age (18-21, 22-27, 28-32, 33-40, 41 and older). Other studies have varied in their age ranges assigned to each career stage, however typically the early career is associated with an age range of 20 to 34 years, the mid-career stage from 35 to 50 years and the latecareer stage from 50 to 65 years (Kaur \& Sandhu, 2010).

Career stages can also be categorised in other ways such as using tenure (Mowday, Porter \& Steer, 1982; Reichers, 1986). Tenure is regarded as an 'organisational age' or the length of time that an individual has been working in an organisation and is representative of the amount of experience within the organisation (Kaur \& Sandhu, 2010). This career stage indicator was developed by organisational commitment development models, which "suggest that tenure causes changes in behaviour and attitudes towards work" (Kaur \& Sandhu, 2010, p. 143). Based on these models, there are four career stages: the pre-entry stage, the early employment stage, and the middle and late-career stages (Mowday et al., 1982). Reichers (1986) offered a similar model however, he focused on the early, mid and late career stages and did not include a 'pre-employment' stage. Ornstein et al., (1989) argue that when tenure is used as the measurement for career stage, then the first two years in a job are a 'trial period'. Then from two to ten years is the establishment phase, followed by a maintenance period from ten years onwards. The establishment period is when the individual focuses on advancing and growing their career, while in the maintenance period they focus on holding onto the accomplishments they have achieved so far. Finally, Greenhaus, Callanan and Godshalk (2000) argue that there five stages in an individuals' career development which are based on age, working experience and tenure. The first stage is 'occupational choice', where the individual prepares for work. This is followed by 'organisational entry' which is similar to Ornstein et al.'s (1989) two-year trial period. These two stages are followed by early-career, mid-career, and late-career stages, much like the models developed by Super (1957), Reichers (1986) and Ornstein et al. (1989). 
Although the effect of career stage has not been examined directly in relation to emotional management, it has been examined in relation to some of the consequences of emotional labour such as organisational commitment (Kaur \& Sandhu, 2010), work commitment (McElroy et al., 1999), burnout (Cannizzo \& Liu, 1995), job satisfaction and well-being (Burke, 1989). The majority of these studies find that when an individual is in the midway stage of their career they had the greatest stress, the least job satisfaction, greatest burnout, most work-family conflict and reported the most negative work setting (Burke, 1989; Cannizzo \& Liu, 1995). These results show a curvilinear result between career stage and the measured outcome and tend to be unrelated to the age of the individuals.

The literature examined on career stages, will be used to help base how this research will define career stages for academia. As will be discussed subsequently in this chapter, academia is a unique profession in many ways and therefore careful consideration will be needed to define their career stages.

\section{Emotion at work in Academia}

Emotion work has now been widely studied in many different sectors and organisations (Mann, 1997). Predominantly it has been studied in caring and service sectors which are dominated by female staff such as nurses (for example Cricco-Lizza, 2014), other health care professionals (Mann, 2005), flight attendants (for example Hochschild, 1983), teachers (for example Jenkins \& Conley, 2005) and store clerks (for example Sutten \& Rafaeli, 1988). Females are typically viewed as the 'emotional' gender and it is argued that they tend to work in caring sectors where emotional labour is performed more (Kruml \& Geddes, 2000). More recently, attention has turned to sectors where emotion is not as immediately linked with the work role such as adventure guides (for example Sharpe, 2005), and male dominated sectors such as policing organisations (for example Martin, 1999), where emotional labour is prevalent yet understudied due to views that males are less 'emotional' (Kruml \& Geddes, 2000). Key issues of concern in many of these studies look at the negative consequences of emotional labour such as burnout, stress, job satisfaction, work commitment, absenteeism, depression, substance abuse, and diminished self-esteem (Grandey, 2000; Hochschild, 1983; Pugliesi, 1999; Rafaeli, 1989; Zapf, 2002). Academic work on the other hand has garnered less attention. As will be discussed, academia provides a unique and interesting case for exploring emotion at work and in this 
section, I examine academia in regards to emotion work, coping strategies and career duration in order to build the context for this research.

Generally, academic staff are required to "divide their time between teaching, research, service, and for some, administration" (Bellas, 1999, p. 96). Academics regularly engage in face-to-face or voice-to-voice contact with an array of people including students, colleagues, administrators, and occasionally members of the public. Bellas (1999) explains that while academic staff tend to have considerable autonomy, they also have control exerted over them via performance evaluations and other such methods. As discussed in chapter one, the changing nature of academic work requires new thinking about the shifting emotional demands on academics.

\section{Emotion work and academia}

In order to be effective teachers, academics must create a positive learning environment (Schmisseur, 2003), and to do so their job requires them to "induce or supress feelings in order to sustain the outward countenance that produces the proper state of mind in others" (Hochschild, 1983, p. 7). Simply put, they must perform extensive emotional labour and emotion work and this includes to "emote feelings of enthusiasm, happiness, confidence, self-assurance, and passion about and satisfaction toward teaching" (Zhang \& Zhu, 2008, p. 106; Winograd, 2005). Ogbonna and Harris (2004) argue that emotional labour for academics has increased due to the "heightened intensification of the academic labour process" (p. 1185). Constanti and Gibbs (2004) identify that academics are required to perform emotional labour in order to meet two primary outcomes; customer (the students) satisfaction and profit for management/ the organisation. It is important to note that Constanti and Gibbs, (2004) propose that "it is taken for granted" (p. 247) that the academic will perform emotional labour when interacting with students in order to benefit the student and the university. However they also note that in order to perform emotional labour the academic must possess certain qualities and/or traits which are "neither evaluated nor rewarded, or indeed counter to [their] academic authenticity" (Constanti \& Gibbs, 2004, p. 247).

Academics engage in a wide array of activities in their jobs, and each job requires different levels and different types of emotion work (Bellas, 1999). When teaching, the academic must "motivate and stimulate student interest" (Bellas, 1999, p. 98) and to do this they 
must employ certain skills. In some cases the academic may "thrive on teaching" (Bellas, 1999, p. 96) and therefore may be genuinely acting as they are able to express the appropriate emotions naturally (Ashforth \& Humphrey, 1993). However, for those academics that are less focused on teaching or are having a bad day, they will have to perform emotional labour in order to complete their job appropriately (Bellas, 1999). McKinney (1988) even proposes that academics should "show a sense of humor, wear diverse and visually interesting clothes, alter [their] vocabulary, and make use of paralanguage and nonverbal behaviours (gestures, facial expressions, body movement, eye contact" (p. 300). Seldin (1980) explains that academics will need to show "empathy, warmth, intuition and flexibility" (p. 121) when advising students and, that they should have "the ability to give as much time as necessary to counsel students on courses, careers, and personal problems" (p. 121). Bellas (1999) notes that academics are more than likely not trained counsellors and yet, they may still be expected to engage in emotional labour and emotion work and listen and talk to the student about their problems. Bellas (1999) demonstrates that in student evaluations, professors are often criticised for not displaying the appropriate emotions or behaviours. Alongside displaying the appropriate positive emotions, academics must also control their own and their students' negative emotions, such as impatience, annoyance and anger (Bellas, 1999). Students can also approach academics outside of their teaching time, for example, they may approach an academic in their office for some advice.

As well as teaching, academics also engage in service work, which can entail a wide array of activities such as public relations, student advising, committee work, reviewing manuscripts for journals and student-faculty interactions (Bellas, 1999). This type of work is important for an academic to enhance their career, facilitate research and build networks. In order to engage in favourable and beneficial interactions, emotion work will need to be performed (Bellas, 1999). These service activities are also important because while they, in themselves, are not financially rewarded, they can lead to a higher status and higher salary "by attaining visibility within institutions" (Bellas, 1999, p. 102). Serving on a committee also requires many social and emotional skills (Bellas, 1999). It is important to note that when serving on a committee the emotional labour required may differ depending on several factors such as the issues being discussed, the level on consensus on a topic and power dynamics within the committee (Bellas, 1999). Bellas (1999) assesses that, individuals will have to perform emotional labour in order to "show respect for differences 
of opinion" (p. 103) and to "exhibit cordiality" (p. 103), as well supressing negative emotions at times.

Emotion work is also performed when academics conduct research, although research seems to "involve little emotional labour relative to teaching and service" (Bellas, 1999, p. 104). It is often thought that emotions can impede the science and objectivity of the research process and this could be why emotion in research work is not widely explored in the literature (Bellas, 1999). Babbie (1995) deduces that when conducting research with participants (such as research interviews) the researcher (interviewer) should be a "neutral medium" (p. 264) and they should not display emotions so that they do not influence the participants' responses. However, the interviewer also needs to make the participant feel comfortable and at ease (Bellas, 1999), and so emotional labour is important in maintaining the right emotional balance in this situation. Bellas (1999) explains that it can also be hard for the researcher to remain neutral, especially when the researcher feels strongly about the research topic or the topic is emotionally charged. She states that the "interview experience can elicit powerful emotions in both the interviewee and the researcher" (Bellas, 1999, p. 105). There are significant demands here for the academic to manage their own emotions. Quantitative research can also involve emotion work even when the research will use only secondary data (Bellas, 1999). This is due to the fact that academics can become highly invested in their research and they "must manage their emotions regarding the interpretation and potential impact of their findings (Bellas, 1999, p. 105). This can involve deep acting as a way of distancing themselves from potential emotional issues (Bellas, 1999). Research can also involve contact and collaboration with research assistants, other academics, and journals. This involves the need for communication and interpersonal skills and often involves higher levels of emotional labour (Bellas, 1999).

Academics often also present their research to other academics in conferences, journals and classes (Bellas, 1999). The emotional stakes in these situations are high, as a "poor professional presentation may have negative consequences for one's reputation" (Bellas, 1999, p. 106). In these instances, the academic must use clear communication and engage the audience and elicit positive emotions in their audience while simultaneously supressing any feelings of fear or anxiety. These events are also recognised as important for networking and for promoting their academic work to others (Bellas, 1999). 
Finally, emotion work is also performed during many of the administrative tasks that academics do (Bellas, 1999). This can involve "activities such as preparing budgets and reports... supervising subordinates and reporting to people in higher positions" (Bellas, 1999, p. 106). Again, these tasks require strong communication skills and interpersonal skills as well as leadership abilities.

The literature on emotional labour for academics in higher education is limited (Constanti \& Gibbs, 2004) and a better understanding of emotional management and the role of emotion is needed in higher education and teaching in order to lower emotion related turnover rates (Zhang \& Zhu, 2008). Schmisseur (2003) also identifies that the emotional terrain in higher education is still greatly unknown and requires a better understanding despite the increased recognition of the importance of emotion in the workplace. This project aims to first map the emotional content of academia in relation to specific contextual factors.

\section{Outcomes}

Engaging in emotion work can have a variety of consequences for academics and as with other professions, the outcomes can be both negative and positive (Zhang \& Zhu, 2008). The demands made by customers and management to perform their job well, means that academics will engage in emotional labour. Subsequently, these demands "means tensions occur and exploitation potential appears" (Constanti \& Gibbs, 2004, p. 248). Zhang and Zhu (2008) found that academics engaged in deep acting the most, followed by genuine acting, with surface acting being performed the least. If an academic is conducting research over a longer period of time there is a risk of them becoming emotionally involved in their subject's lives (Bellas, 1999; Corbin, 1971). This can heighten the potential consequences of the performance of the emotional labour.

\section{Negative consequences}

In their study on Chinese academics Zhang and Zhu (2008) found that surface acting had negative impacts on burnout and satisfaction, and can lead to depersonalisation. In their study on work intensification and emotional labour for UK academics, Ogbonna and Harris (2004) found that performing emotional labour led to academics experiencing "feelings of inadequacy at having to 'fake' emotions in order to cope with seemingly legitimate demands" (p. 1198). They also note that these feelings of inadequacy and guilt 
led to higher levels of stress, and such negative impacts of emotional labour were heightened by a lack of emotional support from their colleagues as a result of lower levels of colleague interactions (Ogbonna \& Harris, 2004).

\section{Positive consequences}

In their study on Chinese academics Zhang and Zhu (2008) found that in contrast to surface acting, deep acting and genuine acting had positive impacts on burnout and satisfaction. They also note however, that while genuine acting typically involves expressing positive emotions, it can also result in the "spontaneous expression of negative emotions" (Zhang \& Zhu, 2008, p. 117). It has also been suggested that the performance of emotional labour helped academics to cope with work overload and to resist increasing managerialism (Ogbonna \& Harris, 2005; Willmott 1995). Ogbonna and Harris (2004) identified that emotional labour had a positive consequence for academics in organisations where "career progression was linked to their ability to sustain a "professional identity" (p. 1197). Where teaching quality was highly valued, then emotional labour helped academics to maintain an image of 'genuinely' caring for their students and this, in turn, was rewarded by the organisation (Ogbonna \& Harris, 2004).

\section{Career duration and academics}

As noted earlier, within any working life and in any occupation, people will go through "typical evolutionary phases called career stages" (Kaur \& Sandhu, 2010, p. 143; Super, 1957). This is no different for academics even though academic careers are "fairly unique" (Dowd \& Kaplan, 2005, p. 699), and may develop differently to other occupations (Cytrynbaum \& Crites, 1989). It has been argued that academics will skip the 'exploration' career stage and start their career in the 'establishment' stage, as graduate school is seen to be where the exploration phase is carried out (Cytrynbaum \& Crites, 1989).

It is also important to note that many people enter into academia after a career in a related field of work, and in this case a broader theory of faculty career may be needed (Baldwin, 1990; Cytrynbaum, Lee \& Wadner, 1982; Schuster \& Wheeler, 1990). Baldwin (1990) emphasises that faculty careers are an evolving process in which individuals will experience different developmental needs at different career stages. Much like the majority of other research on career stages, Baldwin (1990) describes the academic career as a progression over time through a series of stages. Cytrynbaum et al., (1982) propose that in 
order to outline the distinctive challenges faced by academics then a life-span approach should be used. Comparable to this argument, Schuster and Wheeler (1990) argue that a broader and more flexible career model should be developed for this context.

It has been found that many behaviours and attitudes will change over the duration of an academic's career. Ladd and Lipset (1975) concluded that political attitudes were distinctly different between older and younger staff, while Blackburn (1972) found that attitudes varied depending on the career stage. Fulton and Trow (1974) explain that role preferences also changed over the duration of a career, as did workload and productivity (Bayer \& Dutton, 1977; Blackburn, Behymer \& Hall, 1978; Pelz \& Andrews, 1976; Thompson, 1971). It is important to note that much of this literature is at least 30 years old and with the changing face of the academic workplace, some of the extant research may no longer be reliable. With many of these aspects documented as changing over an academic's career duration, it seems likely that coping strategies for emotional labour will also change over the duration of an academic career. In support of this, Ogbonna and Harris (2004) claim that academics used display rules as a form of coping mechanism for intensified expectations. However, they found that academics in the later career stages found that these coping mechanisms were not needed at the beginning stages of their careers. Consequently, they argue that emotional labour is used as a defensive response to a higher workload as academics proceed through their career.

Taking into account the extant research, for this project the career stages used are as follows: early-career ( $<7$ years in academia), mid-career (7-14 years) and/or later-career (>15 years) stages. The years indicated are approximate and participants will also be asked to self-define their career stage. Across these groups I also consider age and organisational level given that these dimensions do not necessarily coincide with career-stage within academia. 


\section{Summary}

This literature review has discussed emotion and its various forms within the workplace. An overview was given on the consequences of performing emotion work. Leading on from this, how employees cope with the emotional demands of their work was explored. The review then examined how career stages are categorised in the literature. A brief overview was then given of how emotion work has been studied in other sectors and this led on to examining emotion work for academia.

Key questions remain in regards to coping strategies and with specific reference to academia, the literature is sparse; moreover as there is no literature which examines the relationship between the career stage/career duration of academics in relation to emotional in the workplace. The proposed research question for this study is thus: What are the emotional demands experienced by academics in the workplace and what strategies do they use to cope with these demands? I also seek to answer a secondary research question: How do these strategies develop and change over the duration of their career? In the following chapter, I will explain the research methodology and design to explore these questions before I go on to draw out answers to these questions in chapters four and five. 


\section{Chapter 3: Methodology}

\section{Introduction}

In the previous chapter, I established the theoretical space to which I intended to make my contribution. The review of extant literature showed that studies on emotion in the workplace are largely quantitative, while qualitative studies are limited. There is little research on the strategies that individuals use to cope with emotional demands of their work and there is even less research on how coping strategies may develop and change over the course of academic careers. This is an exploratory study, which aims to seek rich data and to understand people's experiences. Below, my ontological and epistemological orientation to this research will be discussed first, before going on to discuss the rationale for choosing a qualitative research approach for this study. Next, I discuss my approach to analysis and the research paradigms and assumptions it rests on. The chapter then goes on to explain the method in detail including the recruitment of participants, the data collection methods, and the data analysis methods. The chapter concludes by discussing ethical considerations for the research.

\section{Ontological and epistemological orientation}

As the prior research on emotion in the academic context is limited, an exploratory study was conducted adopting interpretivist epistemological and social constructionist ontological stances.

Ontology is "the study of what exists, and how things that exist are understood and categorized" (O'Leary, 2014, p. 5). Social-constructionism emphasises that our understanding of the world is "constructed by human beings as they interact and engage in interpretation" (O'Leary, 2014, p. 7). The social-constructionist position follows several key assumptions (Burr, 2003). It insists that we must be critical in our observations and to question any assumptions. This stance also urges us to realise that knowledge and understanding are culturally and historically relative and thus knowledge is an artefact of a particular time and place. Social constructionism also guides us to realise that knowledge is constructed between people and their interactions and it is sustained through social processes. By taking a social constructionist approach, my ontological position emphasises that reality is created through relationships and the social interactions between people. I 
deem the reality of emotion work to be constructed, and reconstructed, from the perceptions, interpretations and actions of the academics throughout their career. Social constructionism is appropriate for my research, as emotions can only be understood through the perceptions of the individual rather than observation. This is due to emotion being personal to the individual and often internal (Ashforth, 2000).

Epistemology is "how we come to have legitimate knowledge of the world; rules for knowing" (O'Leary, 2014, p. 5). Consistent with the qualitative design of this research and following on from my ontological position of social constructionism, is my epistemological position of broad interpretivist. The interpretivist approach aims to "gain understanding by interpreting subject perceptions" of a particular phenomenon (Denzin \& Lincoln, 2011, p. 102). Guba and Lincoln (1985) state that "social reality is a construction based upon the actor's frame of reference within the setting" (p. 80). This position assumes that "people construct their own understanding of reality" and that "we construct meaning based on our interactions with our surroundings" (Denzin \& Lincoln, 2011, p. 103). As such we cannot be separated from what we know (Guba \& Lincoln, 1994) and subsequently, "we are shaped by our lived experiences, and these will always come out in the knowledge we generate as researchers and in the data generated by our subjects" (Denzin \& Lincoln, 2011, p. 103). The aim of my research is to explore emotion work through the academic context by interpreting the experiences of academics' emotion. The interpretivist approach also looks towards the feelings and meanings behind actions (Bryman \& Bell, 2011) and thus is suited to this research exploring the experiences of emotion work and how academics cope with the increasing emotional demands of their work throughout their career.

\section{Qualitative design}

Previous studies on emotion in the workplace have often used quantitative research designs in order to gain data from a large and representative sample while aiming to "measure the behaviour and characteristics of that sample, and attempt to construct generalisations" (Hyde, 2000). Many of the early studies have sought to establish generalisations and build knowledge about the concept. More recently, studies have begun to take on qualitative designs as they begin to seek more in-depth understandings about certain groups or particular aspects of emotion work. 
This research is designed as a qualitative study. Qualitative research "emphasizes seeing the world from the viewpoint of the 'actor"' (Hannabus, 1996). These 'actors' are the research respondents or informants whose information forms the basis of qualitative research (Hannabus, 1996). I aimed to generate a better understanding of the emotional demands for New Zealand business school academics and to learn how academics cope with these demands and how their strategies might change over the progression of their career. A qualitative approach is useful in identifying intangible factors and the "human side of an issue" (Mack, Woodsong, MacQueen, Guest \& Namey, 2005, p. 1), inclusive of behaviour and emotion. A qualitative approach will enable me to gain insights into the subjective perception and interpretation of emotion work for academics.

Emotional labour and emotion work are complex social phenomena that are undertaken through interactions between people and through relationships with the individual and their work and/or workplace. Emotion work is a personal experience while still often being social and interactive. It is nuanced and contextual thus qualitative research is appropriate as it provides depth. As Hyde (2000) argues, qualitative research aims to "explain the particular" (p. 84) and allows "the researcher to study issues in depth" (p. 84). As my aim was to produce rich data regarding emotion work for academics over their career duration, a qualitative design is well suited for this research.

\section{Approach to analysis}

In this research, I follow an abductive approach. Hyde (2000) argues that "qualitative enquiry generally adopts an inductive process" (p. 82) however, most qualitative researchers also demonstrate deductive processes as well although they are often not recognised. Inductive processes are theory-building processes where observations lead to higher order theories and general rules about a certain phenomenon. Deductive processes are theory-testing processes where the researcher seeks to determine whether a preestablished theory can apply to certain instances (Hyde, 2000). Abductive approaches sit between inductive and deductive on the continuum. Abductive processes are a "process during which the researcher, as it were, eats into the empirical matter with the help of theoretical pre-conceptions, and also keeps developing and elaborating the theory' (Alvesson \& Skoldberg, 2009, p. 5-6). Thus, I will use extant literature to guide the analysis of the data, while striving to develop new ideas and theories. 
In this research I am exploring how academics experience emotion in the workplace and collecting data through in-depth interviews with business school academics. The primary purpose of this research is to examine how academics experience the emotional demands of their roles and the coping strategies they adopt to cope with the effects of emotion work. I then aim to explore whether these coping strategies change and develop over various career stages. This takes an inductive approach where the generation of theory is developed through observation and data findings (Bryman \& Bell, 2011). However, my analysis for academics takes an iterative approach by moving back and forward between the literature and the data while checking and refining theory. This research will begin by using a deductive approach in which previously developed emotion work and emotional labour concepts will be used as a foundation for the research, while an inductive approach will be used to interpret the data and test against extant knowledge.

As the literature review showed, there are many ways to conceptualise emotion work, however our understandings of emotion work have developed and advanced through theoretical conceptualisations in previous literature. This is akin to deductive processes and it is practical for this research as emotion work is a complex concept and thus conceptual guidance is needed in order to explore emotion work for academics.

To summarise, the theoretical approach for this research will take on an abductive approach which includes iterative inductive and deductive processes. I believe that this combination of both induction and deduction suits the design of this research and will enable me to achieve the research objectives. Parke (1993) states that it is important for all research to balance out a mix of both induction and deduction. The absence of deduction could mean that the research is deprived of concepts and theoretical perspectives, which could aid the study of a phenomenon and refinement of theory. Whereas using only deduction could hinder the development of new theory.

\section{Method}

The subsequent sections of this chapter will discuss the method chosen for this research. This includes participant recruitment, the data collection method; interviews, the interview schedule and the method for data analysis. Concluding the chapter is an overview of the ethical considerations and limitations of this method. 


\section{Participants}

The characteristics of my desired participants were New Zealand Academics from within business schools in the New Zealand tertiary education sector. The choice of business school academics was to minimise the challenges of identifying and dealing with interdisciplinary differences of the emotional context of work such as levels of student engagement. I needed to ensure that I recruited participants from each career stage and in selecting participants I needed to conduct enough interviews to draw out variations of the academics emotional experiences in their workplace. Variation is important to gain as "there is likely to be more than one way to experience any particular phenomenon" (O’Leary, 2014, p. 139).

To recruit participants from New Zealand business schools, the snowball sampling technique was utilised. I started out with a handful of initial contacts across New Zealand, given to me by my supervisor. An introductory email was sent to these six people. This email outlined the project's intentions, the likely time commitment and invited them to participate in my research. The email then outlined that I was using snowball sampling and asked if they could recommend any other potentially willing colleagues in their faculty across the three defined career stages. A participant information form was also attached to this email, outlining the project in more detail. The second stage involved contacting those people who were recommended to me by the contacts. Again, an email was sent outlining the project details, their likely time commitment, inviting them to participate in my research, explaining my use of snowball sampling and finally asking if they could recommend any other potentially willing participants. In total I contacted a further 17 potential participants. At no time were the identities of those willing to participate made known to those that have recommended them or to any other person.

From some of those I contacted, I received no response from, even after follow up contact was made. There was only one participant who responded stating that they were unable to participate in the research, however they did recommend several other people whom I could contact. All the other people that were contacted were willing and able to participate in my research however, there was a number of people who were willing to participate but were not needed once I reached saturation in my data collection. In total eleven business school academics were interviewed. I acknowledge that my respondent pool is limited in number and is not representative across the entire academic field. It reflects the limited 
scope of this project and approach to provide in-depth analysis with an exploratory project rather than create generalisations.

I conducted interviews with both male and female academics and in total I interviewed 11 participants. I used a cross-sectional panel design to gather data from academics from three career stages (3-4 participants in each stage). The career stages are adapted from other studies and are as follows: early-career ( $<7$ years in academia), mid-career (7-14 years) and/or later-career (>15 years) stages. The years indicated are approximate and participants were also asked to self-define their career stage. Across these groups, I also considered age and organisational level given that these dimensions do not necessarily coincide with career-stage within academia.

\section{Data collection method}

There are several methods of data collection, which are appropriate for qualitative research for example; surveys, interviews, observation, and focus groups (O'Leary, 2014). After considering these different options, semi-structured interviews were chosen for the data collection method for several key reasons. The reason for this choice was to gain insights into particular experiences of the respondents and to learn from them things which cannot be observed directly (Patton, 1990). Secondly, through semi-structured interviews the experiences of the individual participants and their reflections of emotion in their work environment can be analysed. Furthermore, semi-structured interviews allow the interview to carry out as more of a 'conversation' with a natural flow, which is often the goal for phenomenological studies (O'Leary, 2014). This choice also allowed the interview schedule to be developed by building on extant knowledge.

Finally the choice of interviews for data collection was also influenced by time and cost restraints. Due to time and cost restraints participant observation was not feasible. Surveys are less suitable for generating in-depth understandings in exploratory projects. Conducting a focus group was considered but would not have provided as valuable data as an in-depth interview. Furthermore, it is notoriously difficult to coordinate organise a time and place to suit all the participants, especially considering the timeframe for this research project. Focus groups would have allowed data collected from a wider range of experience but in depth interviewing would have been inappropriate due to the public nature of the process (DiCicco-Bloom \& Crabtree, 2006). 
As I was conducting interviews across different locations in New Zealand, participants were informed of the dates when I would be in their area and then the interview location and time was decided by the individual participants. All participants chose for the interviews to take place in their personal offices within work hours. Participants were made aware that the research has been approved by the Human ethics committee and they were given an information sheet to read which again outlined the project details and intentions (see Appendix 1). Participants were given the opportunity to ask questions before signing a consent form at the beginning of the interview. The interviews were electronically recorded with the participant's permission so that they could later be transcribed. Interviews times ranged from 45-90 minutes.

\section{The interview schedule}

As discussed, the interview guide (see Appendix 2) was designed as semi-structured, allowing me to ask the respondents similar questions so that the interview results could be easily compared, while also allowing for "spontaneous reactions of the respondents" and to allow the interview to be "adapted to the level and personality of the respondents" (Hannabus, 1996, p. 23). The semi-structured design also allows for other questions to emerge from the conversation, which can give a better understanding of the respondents' perspectives (DiCicco-Bloom \& Crabtree, 2006). The interview guide was designed to fit with my social constructionist approach and the questions were designed to allow the perceptions of the individuals to be explored. This was important as with the social constructionist approach I deemed that the reality of emotion work is constructed, and reconstructed, from the perceptions, interpretations, and actions of the academics throughout their career. The guide was also built on knowledge from extant literature, explicitly picking up on emotion in the workplace, coping strategies and career duration.

The guide started out by asking the participant general questions about their career trajectory and general work duties. The questions subsequently became more focused with a series of questions regarding emotion for the participant in their workplace. Questions then inquired into how the participants coped with managing their emotions, the availability of workplace training for dealing with emotion, and general summary questions to round off the interview. 
Method of data analysis

My aim for the data analysis was to generate new understandings of how academics cope (strategies) with their emotional demands at work and how these coping strategies changed and/or developed over a career. As explained earlier, abductive thematic analysis was justified as the most appropriate method to process and analyse the data gathered in the interview process. Thematic analysis is a widely used method of qualitative data analysis (Braun \& Clarke, 2006) and it "provides a flexible and useful tool to identify and organize key themes from qualitative data" (Bischof, Warnaar, Barajas \& Dhaliwal, 2011). The themes are developed through the identification of recurring words or concepts and looking for patterns or interconnections (Braun \& Clarke, 2006) and this process is explained in depth in the following sections.

The '6-phase guide to doing thematic analysis' developed by Braun and Clarke (2006) was used to guide the data analysis in this research. Braun and Clarke (2006) note that this thematic analysis can start during the data collection phase as the interviewer starts to identify themes while interviewing participants. Furthermore, they note that the process involves continuously moving back and forth over the entirety of the data, the coded sections and the data analysis that has already been produced.

\section{Phase One: Familiarising yourself with the data}

The first step in the data analysis process after collecting the data was to organise it. The interview recordings were first transcribed verbatim (by the primary researcher). This was a time-intensive process, which required listening to small sections of the recordings several times over then typing the conversation up. The data was then read over several times in order to create familiarisation and notes were made where important.

\section{Phase Two: Generating initial codes}

The second step of thematic analysis involves allocating specific codes to features of interest across the data set, then collating the data, which are relevant to each code. This process was done manually using pens to write on printed copies of the data sets. This coded data is different to the themes developed in step three, which are broader. To code the data it was useful to approach it with specific questions in mind. The method employed was to use different coloured pens to identify potential patterns, which allowed them to be easily collated. 


\section{Phase Three: Searching for themes}

The third step is to collate the codes generated in step two, into potential broader themes. This involved collecting all the data together, which could be relevant to each potential theme. The codes were assembled into a list before starting which were then cut up into individual pieces of paper for each code. When a new theme was identified, the codes were checked to see if any fitted into that theme. Any that did not fit were left and codes that did fit were grouped together in a pile. As more themes were identified, the codes that were left were checked to see if they fitted into the new theme. At the end of the analysis any codes which did not seem to fit into any of the themes or sub-themes where grouped together and labelled as 'miscellaneous'.

\section{Phase Four: Reviewing themes}

The first level of this step involves refining the themes developed in phase three. To do this, the coded data for each theme was examined to see if they formed a clear pattern. If the pattern was not coherent, it was then considered if it was the theme that was problematic or if some of the coded data did not fit into the theme. If the theme did not work then the theme was either reworked or a new theme was created which worked better. If the coded data did not fit the theme then they needed to be moved to another theme, which suited better or move them to the miscellaneous section. In this phase, some themes were also combined together and some themes were removed, as they did not have enough supporting data. Any contradictory information was then explored and if necessary, the themes were revised. This step also involved exploring the relationships between the themes and working out how these themes would help to answer my research question. At this point, using abductive processes, this step involved moving between extant literature and the data to refine the themes. The second level of this step involved reviewing whether the themes accurately represented the data set as a whole. Some further refinement of the coding was then undertaken before my final themes were developed.

\section{Phase Five: Defining and naming themes}

This step involves creating names for each theme and developing a definition to suit each theme. This step was essential in developing the overall picture that the analysis shows and involved identifying what the aspect of the story each theme shows by identifying what is of interest and why. Throughout this process it was also important to consider how each theme relates to the other themes in order to build the whole story. 


\section{Ethical considerations}

There were several ethical considerations to take into account when conducting this research. Ethics involves "the interaction and relationship between the researcher and the subject as well as the effect inquiry research has on populations" (Denzin \& Lincoln, 2011, p. 103). The key ethical considerations for this research were informed consent, participant confidentiality, and imploring to avoid any emotional harm to participants.

Prior to the interview, participants were given an information sheet (see Appendix 1) which outlined the details and scope of this research project. They were subsequently given the opportunity to ask any questions and raise any concerns. They then signed a participant consent form (see Appendix 3) and filled out a demographics form (see Appendix 4), agreeing to the interview being audio recorded and stating that they understand the project and have been given the opportunity to ask questions. The consent form also provided the participants with a possible withdraw date.

Participant confidentiality is an important ethical consideration as during the interview the participant may potentially "share information that could jeopardise his or her position in a system" (DiCicco-Bloom \& Crabtree, 2006, p. 319). In order to maintain participant confidentially when reporting the data Pseudonyms have been used. As the participants are from business schools nationwide, there is less chance of participants being identifiable to any particular group. If my supervisor or I had any concerns about whether disclosure of particular information would make someone identifiable I contacted the participant and checked with them. Participants were advised of this and the participants gave informed consent through a signed consent form. As previously mentioned, snowball sampling was used to find potential participants for this research. This process was conducted carefully, and in a way that participants did not know whom else had responded to the research or who was participating.

If participants are extremely new to their organisation then some statements that they make could potentially make them identifiable to their supervisors and/or colleagues. I ensured to take a great amount of care in reporting details that could make an individual identifiable in order to minimise this challenge. Participants were also sent a copy of the interview transcripts in order to ensure authenticity and to ensure that they were happy with what was reported. As all of the participants chose for the interviews to take place at 
their workplace (their office) then there is a slightly increased chance that other individuals could determine some of the people participating in the interview, as they may have seen me interacting with some of their colleagues or entering their offices.

The interview schedule asked participants to recall stressful and emotional situations and to describe how they dealt with them. Due to the nature of these questions, it was possible that interviewees could become anxious or upset by recalling stressful situations. I was aware of this and the interview was designed to be balanced and it was likely to trigger happy and positive emotions and feelings as well as emotions that are more negative. DiCicco-Bloom and Crabtree (2006) note that "investigators must be prepared to provide psychological support if their interviews create undue stress or raise psychological complications" (p. 319). Prior to the interview I advised them of this risk to them, and presented them with support options should they experience any distress either during the interview or at a later stage. At the conclusion of the interviews no participants requested or required the support options presented to them before the interview.

\section{Summary}

This chapter discussed the methodology used for this research project and explored how it has influenced the data collected. This chapter explained the qualitative nature of the project that used semi-structured interviews to gather data from 11 academics from New Zealand business schools. The data was analysed using thematic analysis. Aspects of this design had specific limitations such as the sampling technique and a small sample size, which will be discussed in chapter six. 


\section{Chapter 4: Causes of Emotion for Academics}

\section{Introduction}

This research set out to explore the emotional demands that New Zealand business school academics experience in the workplace. Additionally it sought to examine the strategies used by academics to cope with these demands. I have argued that this research is important due to the increasing emotional demands on academics. There is currently limited research showing how academics cope with the emotional demands of their work, and there is no research showing how these strategies are developed and how they change over the course of their careers. This chapter first examines how academics experience emotions in their workplace and shows the consequences that these can have. It will show that while there are similarities across the career stages, there are also some important differences. Chapter five will then go on to explore the coping strategies used by academics and the support they feel from their workplace. Throughout the following chapters I refer to participants using a pseudonym and their relevant career stage; early career stage (ECS), middle career stage (MCS) and late career stage (LCS).

\section{Causes of emotion}

In the academic workplace context, the academics interviewed spoke of a variety of emotional challenges associated with their work. Through discussions with participants, three main causes of emotion emerged; personal causes of emotion coming from: 1) the individual, 2) other people in the organisation and 3) systemic causes. When looking across the three career stages there were many similarities, however there was also some variance between the different career stages.

\section{Personal}

The biggest personal cause of emotion for all participants was related to their own research. The range of emotion associated with doing research was varied and ranged from positive emotions when research was going well to negative feelings when research was not going as planned, or the pressure to publish was affecting their research outputs. Miller et al., (2007) described 'emotion toward work' as when 'the object of the emotion is the work or the workplace" (p. 238). They also found that emotion toward work can be both positive and negative and the emotion toward a particular aspect of work can vary over 
time. This was also established in the current research. Henry (LCS) explained how he found this variation:

That's the most energising, when you get on a roll, you get that buzz from writing and thinking something through and saying 'yes, I've got that!' But there often can be many hours of struggle. That's hard.

Academics love the creativity that their role allows them and they enjoy being able to research any topics of their choice. They thoroughly enjoy the reading, discussing, learning, and writing of their research, which are what many academics see as the foundation of their role. Ian (ECS) explained this:

The nature of the job is actually reading, writing, talking and discussing, and this is what I really find rewarding.

The emotions elicited by their research were feelings of joy, happiness, excitement and a sense of accomplishment. In their discussion of emotion toward work, Miller et al., (2007) found that factors such as these, allow employees to find meaning in their work, grow their self-esteem and enhance their personal growth. However, the downside to researching topics of interest to the academics was that they often became heavily emotionally invested in their work. As their research was so personal to them, it often made it hard for them to deal with criticism or rejection of their ideas or their publications. Adam (ECS) explained that as well as getting publications rejected, it was also hard getting criticism of their ideas:

You bounce the idea off somebody and you realise that it's not viable, it's not exciting, it's been done before, things like that. So ideas can get shot down and you can be humbled quite quickly in this game. But more than that, sometimes you write papers, you hire research assistants, get stuff done and then it just gets ripped apart and in my instance my emotional reaction is I'm not sure if this line of work is for me.

Getting criticism often caused academics to feel sad or confused. John (ECS) mentioned that getting criticism can feel like a major loss and he compared the feeling to what he thought a big gambling loss would feel like. Academics described the ways they used to 
deal with the emotional repercussions of these criticisms of their work. Adam (ECS) talked about how often an idea could be reworked to be suitable for another project at some point in the future so that it was not completely thrown out. Daniel (LCS) also used this strategy and if he had a publication rejected he would simply keep working on it and, at some point, submit it to another journal.

Another activity bound in emotion which several participants mentioned was prevalent in their jobs was related to having to assess students and give out grades which were deemed fair. Often the academics mentioned that they felt that sometimes they were being prejudiced and that it was hard to separate their personal opinions of a student from their professional opinion of the quality of the work submitted. Participants described this as stressful and adding to this stress, was concern about how fair they were marking when they had to assess a large number of scripts. Henry (LCS) explained this feeling:

Marking dozens of scripts and trying to still be engaged when you are writing out for the fifty-seventh time "use APA style code" et cetera. There's a certain level of tedium and that's hard.

He then went on to say:

After three hours of marking and I'm faced with another essay and I can tell not a hell of a lot of effort has gone into it... obviously a bit of rushed work, well I rush through it in my assessment. But after three hours how tolerant am I being? And how fair am I being when Abby at the beginning gets so much attention and Zoe at the end gets the short end of the stick? So I've got to watch out for that... So there's a lot of judgment, a lot of assessment, a lot of dilemma, a lot of moral pulling in different directions all the time.

This often caused feelings of doubt in the minds of the academics as they started to feel like they could not trust their own judgement. Henry (LCS) and Belinda (MCS) both talked about the difficulties of this moral conflict, which they often would resolve by stopping their marking for a while and working on something else instead. 
There were also several personal causes of emotion that appear to be unique to academics in the early stages of their career. The biggest of these was the feeling that they had to prove themselves as an academic. Adam (ECS) stated "I want to prove that I can do that job and once I can do that I will be happy within myself'. This also led to having consequences such as feeling as if they couldn't "say no to things" and turn down opportunities, often resulting in an increased workload which was then unmanageable. Ian (ESC) talked about when he first started:

I needed to show that I'm capable of teaching, research, and all these things. This was a bit difficult for the first year and second year, but now I feel more secure. I did my publications, I got good feedback from students and so I am okay now. But it took some time to accept that.

This feeling was echoed by other academics earlier in their career such as Belinda (MCS) who also discussed feeling unable to turn down work when she was in her early career stage. She said:

A lot of people get work piled onto them and other people don't and I think that some people, often senior people, are much better at getting out of doing things than junior people who kind of have to do what they're told or they fear for whether they will ever get anywhere in this world.

Even though they are still in their early career, some had noticed this issue and would advise new academics to turn some work down. Adam (ECS) explained:

I probably made a mistake in overloading with supervisions too quick and I regret that... So I would encourage people not to do that... I was fearful that people would think badly of me if I wasn't showing an unending appetite for work and to contribute. So that was my fear, that they would perceive me saying no as that but now I sincerely regret that. I've got myself in a lot of situations where if I could go back to that moment now I wouldn't have it on my desk. Because there is a long career there and there is no shortage of work at all and it is only a matter of when you get overloaded. 
However, the problem with overloading in work is that once the academics have committed to a project or supervision, then they are fully committed to that, often for a long period of time. $\mathrm{PhD}$ supervision of a student for example, would be a commitment of a minimum of three years for the academic. Adam (ECS) and Belinda (MCS) both show regret at not saying no to more things however, they now feel a sense of commitment to each project and supervision.

There were also several causes of emotion that appeared to be affecting primarily early and mid-career academics. The first was that they would worry what other academics thought about them, their work and how much time they spent at work. They felt that although their job autonomy and flexibility was a great thing, it was also a cause of stress because they worried if others if others thought they were not working hard if they were not sitting at their desk in their office. They also felt extremely anxious when asking for opinions on their work as they found criticism hard to deal with. Evan (MCS) explains:

The thing that I worry about is what other people think of me, colleagues. I don't worry about what students think of me, I worry about what other colleagues think of me in terms of am I doing enough... So that's my main stress probably. That I'm going to drop an important thing and then someone is going to think I'm an idiot.

This seems to be a level of performance anxiety that does not affect academics in their late-career. Academics in their mid-career did not seem as worried as the early-career academics however, they admit that it does still impact on them and does sometimes cause worrying feelings.

Another cause of disquiet which was unique to early career academics was a fear of becoming institutionalised. Adam (ECS) felt strongly about this as he explained:

Another stress is the longer you stay in it, the less able you would be to adjust to a different environment. So you become a bit institutionalised by the way it works and next minute you would be competing against young fresh faced 21 year olds or 22 year olds in industry. So you don't want to become too institutionalised. 
John (ECS) also mentioned that he notices that academics in their later career stages have become institutionalised and he thinks that these people have lost touch with the 'real world'. He explained:

The more time you spend in universities the more disconnected you become, and some people here have some crazy ideas, because they're totally institutionalised.

John deals with this fear and feeling of insecurity by telling himself to not "fall too much in love with this" job and he says that he is continually looking for other opportunities and other things that he could do.

Thus from a personal perspective, issues of morality, integrity and reputation are antecedents of positive emotions such as joy and negative emotions such as fear. For early career academics, in particular there is a sense of the impact that these emotions can have on commitment to their career long-term. This could have potential implications for the rapidly ageing workforce of academia (Sabharwal, 2013).

\section{Interpersonal}

There were two main groups of people that all academics interact with regularly; their students and their colleagues, including co-workers, managers, and administrators. These groups induced a variety of emotion for the academics again ranging from positive to negative. However, these groups also helped to diminish many of the negative emotions that came from either personal or systemic issues. As extant research shows, emotion with work is one of the strongest sources of emotion in the workplace and can induce both positive and negative emotion (Miller et al., 2007). Emotion with work is the emotion caused by relationships and interactions with other people.

\section{Students}

When asked about what the most rewarding aspect of their job in academia was, the majority of participants talked about their students. They described themselves as passionate about their student interaction, which they found to be extremely rewarding, as they loved to see their students learn, develop, grow, and succeed. They feel positive when 
a student comes to see them with their problems, frustrations or stresses and leaves feeling better because of their help. Kate (MCS) explained:

Seeing them succeed, seeing them at the end of their degree go across the stage, hearing when they get a job. Even before that, sometimes you get those lightbulb moments, and all of a sudden you'll see the student, and they'll just click in to what you're saying and they'll start participating in class and getting involved and having an opinion. And that to me is really important because what we teach shouldn't just be content. Our job, I believe, is to actually get engagement from people, get them thinking, get them questioning, get them out into the workplace, so they can actually say, well why do you do it this way and not be too scared to say that. So yeah that's one part of it I really really enjoy.

Other positive feelings involved with interacting with students were surprise and admiration. Kate (MCS) and Evan (MCS) talked about watching students go through difficult times in their lives and still managing to produce great quality work. They often felt amazed with all the various things that students managed to deal with, including living away from their families, student loans, and their workloads. Evan (MCS) recalled a particular student of his who was going through domestic violence in her personal life and was unsure if she would be able to sit the end of term exam. Evan (MCS) said "I said that I would give her an aegrotat score based on the situation if she couldn't attend. She said she wasn't happy with that, she wanted to do her own work. I just had a huge amount of respect for her."

Academics also felt feelings of admiration and pride when their postgraduate students completed their work. They felt like they have seen their students learn, develop, and ultimately succeed. Evan (MCS) explained:

Over there is a stack of theses that students have written. That's pretty rewarding because you watch the interaction of knowledge and it's quite a powerful thing. 
Often, students unintentionally become a source of frustration for many of the participants. Many of the academics interviewed felt like they are working 24 hours a day because they are constantly getting emails from students with queries. Many academics stated that students often have unrealistic expectations and although they want to do all they can to help the students, often the system structures do not allow it. Adam (ECS) explained:

They [students] feel that if they're not happy with their mark, if they don't understand something, then they can email me at any time of the night and expect a response. They're there to contest marks, they want individual feedback for assignments when you might be doing hundreds and you feel like you have given feedback... Students expect that you would have immediate feedback or revisit a situation so that's quite hard.

John (ECS) also felt strongly about this and he talked about the frustration, anxiety, and stress that this caused him to feel. He stated:

It's harder with the students, because they sometimes have unrealistic expectations and... universities have kind of moved from a model of teaching to more of a service and because they show up to a course they feel like they're entitled to an A because they're paying for this and they're the customer. It'd be like me going to a flash hotel and complaining that I wasn't happy with it because I didn't enjoy myself, but they're in control of what their outcome is... So the students definitely become the main feeling of probably anxiety and stress.

This example highlights the changing nature of academia where the students are seen a customer (Waring, 2013). From these comments, it is clear academics see that their roles have changed and that they must make efforts to satisfy their customers; the students, even when they do not think the student is deserving of a good grade or a pass. John (ECS) acknowledged that this often puts him in an incredibly difficult situation and he deals with it by trying to not give it too much of his attention. He explained:

You can only do what you can do... You might respond to something wrong... you might think you're helping, but you might create a whole lot of other 
problems for yourself by answering it, but you just have to move on and not dwell on stuff, because just want to be able to go home and enjoy my life.

John's comments here begin to highlight the potential repercussions of emotionally charged interactions with students. It shows that these have impacts not only in the work context but also in private life.

Academics often found themselves in situations where students would come and see them when they were having troubles with their studies or when occurrences in their personal lives were affecting their work. They often found themselves in positions where they were dealing with upset or frustrated students and the academics had to manage the emotions of the student. Henry (LCS) explained:

\begin{abstract}
Students have hard lives and as a lecturer you are in a parental role sometimes... I've been privy to some pretty sad tales and I can't be indifferent to them, or just put them in a box and move on. So that's quite draining... I think that the role definition can never be very clearly made, the boundaries aren't defined. In some ways I fulfil a lot of roles. I'm a parent, I'm a confidante, I'm a big brother, I'm an authority figure that has to be challenged, I'm a pain in the arse that makes unreasonable demands et cetera.
\end{abstract}

This is a clear example of the conflict that academics often feel in their role. As the teacher, the academic is expected to be authoritative and professional. However, when building relationships with their students, particularly their postgraduate students, there is a personal element in their relationship and this can cause feelings of concern for the academics and make it had for them to be authoritative.

Academics also tend to take on several postgraduate students each year. While also having a sense of pride in these students when they completed their theses, the academics also had to manage many of their frustrations as they worked. Francis (LCS) explained:

The emotional demand is keeping focused with postgrad students, with thesis students, keeping them focused and picking them up when they get a bit 
bowled over by it. Telling them that they can do this stuff, when they turn it in that's it, it's done... I've got one student who is just at the final phases of his thesis and he's getting really frustrated with it. So it's about keeping some focus in that. So you're absorbing their emotional state and you're trying to turn that around, so it's all positive.

Christopher (LCS) also experienced this and when asked about the emotional demands of his students he said that "I perceive them and absorb them". These responses from Francis (LCS) and Christopher (LCS) show a level of emotional understanding that was not evident with academics in their early or mid-career stages. They are showing that they can distance themselves from a situation in order to remove the negative emotion from the student in question and project back a positive emotion. This way of framing their role shows their experience and maturity as academics. They were less likely to question their own abilities in their roles. They understand that "teaching is an emotional experience and you've got to absorb what's coming at you" (Francis, LCS). The academics in their early or mid-career stages however would more typically frame things from a different perspective. For example, they would try to brainstorm different strategies to try and help the student and they would often worry if they were doing the right thing.

This is somewhat demonstrated in Georgia's (ECS) comments relating to the need to provide students with feedback without discouraging them. This feeling was particularly in regard with postgraduate students:

When they've submitted a piece of work and I'm giving them feedback I will try... talk them through, so that I can be monitoring as I'm saying things... because I don't want to demolish their confidence in their work. I'm wanting to make sure that they understand the feedback I'm giving them and it's not because I think their work is shit or there's something wrong, I'm trying to help them move it forward. But getting feedback can be really hard... So I try to be careful around that.

Although less frequently stated, those later in their career did also feel conflict. Christopher (LCS) felt these conflicts in his role as a teacher as he explained: 
The different roles, the different aspects, have different emotional demands. Many of them relate to supporting students whenever they have problems or even when they don't know that they have problems but they are headed for them. For example thesis writing students are often moving too slowly and so one of my emotional demands is whether I should be telling them "hurry up, speed up" when I know it will stress them but when I know that they will be worse off if they don't. Same goes for the level of quality of the work that they are doing. If I can tell that the level of their work is not high enough, do I make them stressed by telling them to improve it and by how much and how hard do I tell them that? Or do I expect that they will improve and try to help them improve but run the risk of them not being able to do so?

Academics had to ensure that they gave feedback to students that would enable them to improve but they had to do it in a way that did not make the students lose confidence in their abilities.

Several academics also mentioned how difficult it is to receive a complaint from a student, even when it was only a minor issue. One participant in particular, talked about the devastation she felt early on in her career when having to deal with a complaint from a student in which the student accused the lecturer of bullying her. Belinda (MCS) explained the situation:

I had a student that decided I was bullying her and that was extraordinarily difficult to deal with from my point of view. As much as nearly every other student would support me and all of your colleagues would support you and everybody knew she was just mad as a hatter, it still escalated through the university and I was left in the dark over a lot of what was going on with it. It was very hard to take, what she was accusing me of, it may have been in her perception but it certainly wasn't in mine. I certainly wasn't doing the things she perceived I was doing to her.

Belinda felt vulnerable, confused and upset as she could not see any justification for these claims and she found this particularly hard to deal with. She even admitted that it was part of the reason she left that job even though she had done nothing wrong. Belinda also felt 
like this situation ended but was never resolved and she admitted that it still affects her and when students approach her about something she sometimes still feels apprehensive. While this is an extreme example of a complaint, other academics did explain how hard it could be to hear criticism from students. John (ECS) explained:

\section{It hits you hard... you could have the best ever survey results on your teaching and one person could say something horrible and it could diminish everything.}

Adam (ECS) also mentioned that when student evaluations occur he feels nervous and anxious with the anticipation of waiting to hear what they say. He also mentioned the relief that he feels when he gets his evaluations back and they are all positive. He explained that although he has not had any negative feedback so far, he thinks it is inevitable and he does not look forward to getting a complaint. He explained:

I always get nervous with student evaluations, but they have been good and I love that, where people say they love the paper and like the teaching style.

\section{Colleagues}

Academics' colleagues were also a source of emotion. First and foremost, all participants acknowledged that their colleagues were a source of support, both emotional and academic. It is important to note however that not all academics provide this support, this support comes primarily from their colleagues with whom they develop friendships. When academics feel that they are not alone in their struggles, they feel a sense of relief. When they become friends with their colleagues, they are provided with feelings of happiness and support. Henry (LCS) said "My colleagues are a source of emotional sustenance, they're supportive and I'm glad I have them." Georgia (ECS) also explains the importance of colleagues:

From my conversations with colleagues I know that this gambit of emotions that I experience is similar to what they experience. So if you find a colleague who's in a more extreme state because of something that's happened, it's kind of, well how do I support them with that and validate their experience, but 
also try and jointly reach our way forward through that in a way that we can survive and not going to run off and slash our wrists [laugh].

These comments from Georgia show that colleagues are a crucial support mechanism and having supportive colleagues is a matter of survival in the academic world. Seeking out such forms of support as a coping strategy will be discussed in the following chapter. Positive emotions arise from colleagues who support each other in the workplace. This aligns with extant research which showed that employees rely on their colleagues for emotional support as their colleagues could understand what they were feeling (Ray, 1987).

However, colleagues' behaviours also generated negative emotions for the academics. Other colleagues playing the system were the biggest cause of negative emotion for academics across all career stages, although this issue appeared to be of more concern for academics in the early or mid-career stages. This occurrence caused academics to feel angry, sad, and frustrated. It was caused when they saw other staff conceding to the system and doing work for purely instrumental reasons as opposed to doing the work they believed they should be doing. It was also caused by staff refusing to work on certain scholarly projects if they did not officially benefit from them. Georgia (ECS) explained:

When I see others conceding to the system and just doing work purely for instrumental reasons, work that they freely will acknowledge is shit work... So when I see or hear colleagues engaging in that kind of instrumental response as their coping mechanism, that I find very isolating because I'm trying not to do that and that makes me really despairing... Like in some sense they've bought into the system and they've said, yeah okay if I do this, if I get my four A publications, I'll get this ranking in PBRF that'll allow me to get this promotion. And some of our colleagues are really open that that's exactly how they are trying to craft their research trajectory and use the system to achieve what they want. They're really naked about that. I don't want to be like that.

This quote clearly shows that emotional demands do not work discretely and there are many overlaps between personal, interpersonal, and systemic causes of emotion. In this 
example, Georgia (ECS) has her own set of moral standards which influences her work. When she sees other academics working outside of what she believes is morally acceptable then it affects her and makes her feel disgusted and angry at their work ethics. As shown, these emotions are exacerbated by systemic influences, which I will turn to in the following section. Again, here there are strong links to extant research where it has been demonstrated that a key component of emotion with work, results from the employees' own perspectives of their colleagues. Individuals all have their own moral code and negative emotions can be caused when they think that a colleague is not carrying out their duties in the 'right' way and as a result they view them as "unethical, dishonest, or unable to pull their weight on the job" (Miller et al., 2007, p. 250). If the individual views the actions of their colleagues as wrong, then this could invoke negative emotions as shown in the example above by Georgia (ECS).

Several participants across the career stages also mentioned the frustration they felt at listening to people complain a lot, who engage in low-level workplace politics and who think they are above other staff members. Several academics also mentioned having to interact with people who they had no respect for, which would often cause them to feel a variety of negative emotions. These frustrations, while they weren't the key stressors for academics were still evident in their roles and sometimes affected their work outputs. Adam (ECS) explained:

There are a lot of dickheads in academia, a lot of selfish, annoying, stupid, irrational, prima donna people type people, there are just a lot of people who would not survive outside of the cocoon of academia, and that these people are protected and move along in academia. It can be annoying and I try and avoid those people in my line of work, but when I do interact with them I find it infuriating.

Another cause of emotion that was primarily mentioned by early career academics, and mid-career academics was the power imbalance in the organisation. They found that some academics of a higher status would abuse their position of power to be of a benefit to them but often detrimental to their more junior staff members. Adam (ECS) explained: 
As people move up the ranks they become more high status individuals and... these people are protected regardless of what they do. Power in academia is very very important... it's not so much about making money, it's about growing your reputation and becoming higher in status... Something that I find very difficult about this job is that status and power rule and some people abuse that status and power because they know that up-and-coming people need to continue up-and-coming so they will do a lot of work and sometimes do so much work that it compensates for their [own lack of] work so they get the fruition of everything.

This power imbalance and abuse of status caused early and mid-career academics to feel annoyed, frustrated, abused, and even angry at times. They felt like they were being taken advantage of and although they acknowledged the hierarchical nature of academia they did not accept when others abused their positions for personal gain. Waldron (2000) argued that interactions with colleagues can involve emotional abuse, for example when employees in positions of power target abuse at less powerful employees. It has been shown that as a result of abuse, employees can be muted when they experience repeated mistreatment (Meares et al., 2004). This appears to relate to these findings where academics in positions of power abuse their position by taking advantage of their junior colleagues, however the junior staff members did not feel they could speak out about the issue.

Perhaps as a result of this vulnerability of more junior academics, those in their later career described that they felt responsibility for other staff members. They felt as though they were in a position where other staff members look to them for emotional and academic support and that this could sometimes be difficult. This was particularly difficult as officially only the head of department was in the position to evaluate staff members but the late career academics felt like more junior academics saw them in this way. They found that this impacted on their relationships with staff members and their previously friendly relationships became more formal and often became strictly professional as late-career academics got promoted. Daniel (LCS) explained:

My relationship with junior colleagues and senior colleagues, is affected by me being a professor... I had a hard time at first because I just wanted to be a 
normal staff member like always... but there is always this part where you are the professor and a senior member of staff which is a little bit different.

This quote from Daniel (LCS) recognises the power imbalance and shows how this imbalance impacts on the late-career academics. They also felt like their status created a barrier and meant that other staff were less open and honest with them and they often found it hard to deal with. Francis (LCS) explained:

I think that the most challenging part of the job is, when a colleague says they're going to do something like this, and then the next week they do something entirely different. That inconsistency is really quite tough to deal with at times. Particularly when you're in a senior role where you're expected to work with them.

He later went on to say:

Duplicity, lying is also something, which I struggle with I think, going behind my back, those sorts of things.

Some of the late career academics also felt that their power status or position also impacted on their relationship with students, although to a much lesser degree. Christopher (LCS) explained:

The higher up you get in rank, the less the students seem to be able to, on the surface, relate.

These quotes show that late-career academics experience a level of isolation caused by their status and tenure. This causes them to have fewer personal relationships with their colleagues and causes students to see them more as purely teachers rather than teachers and friends. This is a cause of anxiety that the other academics had not experienced yet.

Thus from the perspective of emotion caused by other people, it is clear that colleagues and students are a source of both positive and negative emotions. This is largely related to the multiplicity of roles that academics must fill and the changing of their roles over the 
course of their careers. It is also evident that there the personal, and interpersonal factors are highly interrelated with the institutions and the system of academia in New Zealand. Recognition of changing emotional demands within an organisation might be useful as part of management training that those in the later stages of their career could receive.

\section{Systemic}

Surprisingly, the biggest cause of emotion to those interviewed however, was not caused by their personal relationship to their work or their relationships with others, rather it was caused by systemic issues.

The key benefit from the system which made academics happy was their job autonomy and job flexibility. Extant research related to emotion toward work showed that factors such as working conditions, and company policies help keep employees happy (Herzberg, 1976; Herzberg et al, 1959). All academics interviewed for this research loved this aspect of their job as explained by John (ECS):

The best parts of the job are that you get a huge amount of autonomy to do whatever you want and there's lots of flexibility. I could go away, I could not come in today and no one would know, no one would care... That's probably different to any other workplace in New Zealand where you might be managed down to every six minutes, or day, or quarter, or month, or week.

It has been shown that greater job autonomy can help diminish the effects of emotional labour for workers (Wharton, 1993, 1996). This could contribute to the fact that academics still love their jobs even with the daily stresses, frustrations and negative emotions that they endure. Alongside this all academics loved what they saw as the core aspects of their jobs; their teaching and their scholarly work; primarily reading, discussing and writing as Ian (ECS) explained:

I think that being an academic is a privilege in terms of flexible working hours, in terms of the freedom given to you, in terms of it is the place where you can create some assumptions, where you can engage with students, you can touch their lives with some ideas and that's great. When you just look at the job description it's great... If you crown this with further publications, 
further engagement with your colleagues, further engagement with your students, then that's the perfect work life.

These aspects appeared to be the reasons that academics were in this role and why they stayed in their jobs even though they faced many issues. Christopher (LCS) explained that these positive aspects of the job are the reason he stays "because a few good things balance out a whole lot of bad things".

However, the academics often felt that systemic issues sometimes damaged their work and their ability to teach. Georgia (ECS) explained:

The work itself, the scholarly work I love, working with the students I love, but... the context of tertiary education in New Zealand at this point in time, is a really awful context to be working in and it feels like it destroys our chance of doing good teaching and good scholarship.

This is more evidence of the changing nature of academia as explained by Waring (2013), where the institution is commodifying education and the values of the organisation differ to the values of the academic. These systemic issues were felt by academics in all career stages. Often they enhanced and intensified many of the issues discussed earlier. As explained by Henry (LCS):

But emotional demand, I don't feel it as coming from people, I don't experience it as coming from my colleagues, or my boss, or head of school, whoever... I feel it coming from the system, and there's just so much rage around that. Argh, can I say it without choking, the PBRF, which I always refer to as the pernicious bloody ridiculous farce... So yeah... in terms of emotional drain, it's the system.

This feeling of rage was felt by many of the academics and there were two specific systemic issues which were identified as main causes. These were; the pressure to publish and unrealistic expectations. As well as the rage discussed above, these systemic issues also caused fear, anxiety, stress, anger, tension and many more emotions for academics. 
The biggest systemic issue felt by academics was the pressure to publish. Every academic interviewed for this research mentioned that they felt pressure around publications and this was largely caused by the PBRF and intensified by the organisation pushing PBRF as being the main output for academics. Academics felt that their other work outputs and opportunities often suffered due to the increase in pressure to publish a certain number of journal articles and to publish in particular high-ranking journals. They felt annoyance that PBRF evaluated them on where they published their work as opposed to what they were producing. Several academics mentioned that they felt a conflict of interest between what the institution wanted them to produce and what they felt they should be doing. Many academics felt that their time was better spent helping students to succeed, but that the unrelenting pressure to publish meant that their time spent with students was restricted. Academics across the career stages also felt that the pressure to publish reinforced the competitiveness of the organisation, resulting in academics constantly questioning their work and their abilities. Ian (ECS) explained:

There are many aspects behind PBRF. It is the local version of these global audit regimes and it only looks at where you publish, rather than what you publish, rather than what you think, rather than what you try to do, and it makes me sick, to be honest. On one hand I try to resist, but at the same time I am kept accountable on the basis of this audit regime, so mostly I comply, but then this makes me quite unconfident, nervous, and prevented. You try to do something, but you know you cannot do it, just because you feel inhibited. So that's my feeling. So particularly the PBRF makes me really irritated.

These feelings have significant implications for academics in their early career as they are still at the point in their career where they are trying to prove themselves as an academic. Thus adding to the stress and anxiety they feel to perform, they then feel "unconfident, nervous and prevented" (Ian), in the actual work that they are producing. This has potential implications for organisational commitment, which will be discussed further on in the chapter. Ian (ECS) went on to talk about how these performance controls reinforce and intensify the already competitive nature of academia:

The academic job is quite competitive actually and you may notice that some others may achieve very good work, write a good paper, do a very influential 
argument and it's a very personal thing. You may find that, okay how can he do that and why I cannot do that? ... And institutional regimes reinforce these competitive structures, ranking journals, ranking your research and you are quantified with these performance regimes and this always creates a kind of anxiety and tension for yourself. You always question if you are good enough or not good enough.

These feelings were echoed by the other academics, across all career stages. All academics also talked about the unrealistic expectations that the organisation has of them. Academics felt particularly strongly about their high workload, which they felt did not match up with the number of hours in a day, week, month or year. They found that their workloads were so high that they often had to spend a significant portion of their time worrying about what to prioritise and working on their time management. Many academics mentioned that they would have so many things that needed to be done, and that working out which to prioritise was extremely stressful. They also felt that they never completed anything because the jobs were continuous, projects were long-term and as soon as one thing was finished there would be a number more things to do. Francis (LCS) explained:

Never really feeling like you've completed anything is a major stress. Projects take a long time to do and often they change as they're going along. So never quite getting to a point where you feel as though you've done that work... I think the expectations are quite high... I think in this job though you're a kind of micro entrepreneur, so you're dealing with the stresses of doing it all yourself to some degree and with having expectations that are quite high. So you have to come to terms with that in some way. That's a major stress.

As mentioned above, all academics interviewed for this research felt the same about the unrealistic expectations on them. Adam (ECS) explained how the workload did not match up with the number of hours at work that they were paid for each year:

If you just break down the hours in the day versus what is expected of you there is a mismatch. 
Extant research related to emotion toward work showed that negative emotions are caused by factors such as workload, role conflict, and role ambiguity (Miller et al., 1990). This appears to be true for this research as well, as shown in many of the examples above.

Many academics also talked about their expectation to pass students, whether they were deserving of a pass or not. This issue stemmed partly from the changing nature of the tertiary education sector where students are seen more as paying customers (Waring, 2013). If the academic fails a student then the institution loses a customer and their money. Ian (ECS) explained:

\begin{abstract}
Some meetings we are exposed to student numbers, EFTS and all these cost relevant things... it creates another anxiety which really doesn't have any source for me. I have no control over it, but I am exposed to it and we are all reminded how student numbers are important, how we are expected to pass them, not to fail them much.
\end{abstract}

Alongside these key systemic issues, there was a host of other issues stemming from systematic processes that caused negative emotions for academics. Many academics felt that the institutional environment induced fear in the academics and they often felt inhibited in that they could not say what they really felt. Georgia (ECS) explained:

The expression of strong emotion in an official meeting with colleagues is not acceptable. So we can't simply say, I feel so anxious about this PBRF, or I feel so hurt, or damaged, or whatever... that wouldn't be an acceptable way of expressing ourselves... And generally in terms of the concerns that people hold about the institutional practices, that conversation happens between colleagues in offices, over coffee, in corridors, it doesn't happen in official meetings when management are there. So we feel afraid, we don't feel we can say that stuff. To say that stuff, even though we know it's widely held is to mark yourself as someone in the eyes of management who is problematic. It's to invite additional unwanted damaging scrutiny of your work and how you're doing it. So there is clear undercurrent of fear and anxiety that the institutional environment induces. 
Georgia (ECS) was not alone in feeling like this and Ian (ECS) explained how this emotional management leaves him feeling angry:

I would like to show my frustration, disappointment, and anger and I feel that I cannot do this and I know that I cannot do this, and this creates further anger.

All participants who felt this way had to engage in these high levels of emotional management in order to keep their true feelings to themselves. Engaging in this emotional management often had other repercussions for the academics as well, such as the anger and frustration described above.

Unique to late-career stage academics was the feeling of helplessness and frustration at the inability to change systemic issues. Daniel (LCS) explained:

Sometimes there is a mild anger or frustration with things being the same and the same frustration with things that you can't change. So we've been working in this department boosting research for a long time and you find yourself in a meeting where people are talking about how we need to boost research and the same things are coming up and the same problems are occurring and that frustration with things just being the same, like we talked about that 10 years ago and the problem is the same... so it's a frustration that does interfere with your ability to really be positive.

This frustration is caused by the rigidity of the system and the helplessness that the academics feel with their inability to do anything about it no matter how much they try. As the late-career academics have been around for a lot longer than early or mid-career academics, they have seen how some problems have not been addressed over time and even deepened through the introduction of PBRF and this is likely another cause of their frustrations. Late-career academics had worked in academia at a time where the pressure to publish was not as high and where they could freely do the work that they felt mattered the most. 


\section{Outcomes}

The culmination of academics experiencing the causes of emotion discussed above can have a variety of impacts on the mental and physical well-being of the academics. When asked if their job stresses affect their personal lives, all participants except for one latecareer stage academic, answered yes without any hesitation. However, even Daniel, the late-career stage academic who answered no, did admit that there has been times in the past when he has felt affected by job stresses. Most academics also felt that there were certain times of the year, such as the end of year exam period, when they felt particularly affected by their job stresses. Academics talked about spending time outside of work overthinking work problems sometimes resulting in their sleep being affected or their patience would wear down and they would find themselves taking their frustrations out on their families. Adam (ECS) explained:

I do overthink things, so it affects sleep definitely, I wouldn't be a good sleeper often because of work things going on. And it can just lead to physical exhaustion at different times of the year.

Several of the participants also mentioned that the negative side of having a flexible job is that the job boundaries become blurred and it can feel like they are always working. This is enhanced by dealing with students who will email academic at any time of the day and on any day of the week, expecting answers immediately. Francis (LCS) explained:

To finish at 5 and actually go home and just not think about it would be almost unthinkable because it's almost like a 24 hour job. It's always there, you're always thinking about the thing that you're working on. So that has an impact on your personal life.

Another issue that arose frequently was the intellectual nature of their job. As their job is a thinking job, the academics mentioned that it is often hard to switch off even when doing other activities. Henry (LCS) said that "I never switch off. So that's a hard thing".

Several academics mentioned that colleagues of theirs had chosen to take early retirement so that they did not have to deal with the pressure and stress that were caused by all of the issues mentioned above, particularly the systemic issues which were completely out of 
their control. This was described as creating a significant loss of knowledge for the organisation, and because they agreed with the reasons for why these people were retiring early, this added to their feelings of stress. Christopher (LCS) explained:

Another faculty member announced retirement early due to objections of the way that the system was changing and that I would say was emotionally quite stressful because I agree with the person who resigned or retired early because I don't think that the system is changing in the appropriate directions. So I found that emotionally stressful because I agreed with the reasons but I can't retire early, I still need to work for a few more years.

Georgia (ECS) also noticed this issue:

I'm surprised at the number of people who seem to retire early, just because they've had enough. And you go gee there's, 20 or 30 years of wisdom walking out the door. That seems like a bit of a bugger doesn't it.

Finally, early-career academics such as Georgia, Adam and John, appeared to be those most likely to leave the organisation out of all the participants. Although they all loved the key aspects of their job; research and teaching, there were many other factors influencing their organisational commitment. All these participants mentioned that they still did not know if this job was for them, and they did not know how long they would remain in this career. John (ECS) said that while he liked his job, it was never what he saw his career as being and he was still open to other opportunities. While he would like to stay in this job for a while longer, he also mentioned that he did not think that the way that the institution is running is sustainable and so he tries to make sure he does not become institutionalised. Adam (ECS) mentioned that he wants to stay in academia at least until he thinks that he has proven himself as an academic and then he is open to moving on to new opportunities. Like John (ECS) he also has a fear of becoming institutionalised and so he too is open to new opportunities. Georgia (ECS) also does not agree with the way the institution works and she mentioned that if it does continue to function in this way then she will have no choice but to leave the organisation as she cannot continue to function with the levels of stress that she deals with currently. When asked if she sees herself working in academia in five or ten years, Georgia (ECS) explained: 
I'm really unsure about that. I think that if I am I will have found a different way to cope with the demands than I've currently found. Because I don't think I can tolerate sustaining this level of conflict and tension for another 5 to 10 years and I'm absolutely confident my partner will not tolerate me remaining in this state for another 5 to 10 years. So something has to give, either I change how I perceive the situation and how I react to it, or I make some change to my situation.

Such explicit statements highlighting potential to leave were not found with mid or latecareer academics. The difference in organisational commitment between the early-career academics and their colleagues highlights the need for these academics to have coping strategies to help them deal with the emotional demands of their work. Their coping strategies or lack of coping strategies will be discussed in the following chapter.

The findings here have shown the emotion is without a doubt an integral aspect in the role of an academic. The findings highlight the vast array of emotions that academics experience in every aspect of their work lives. The findings show the academics experience emotion as a result of three aspects of their workplace. The first cause of emotion is personal and includes their individual personality, their own work outputs and their work standards and ethics. The second cause is other people, primarily within their own organisation such as colleagues and students. The third and biggest cause for negative emotions was the institutional context and systemic issues. These findings differ from extant research, which shows that generally the largest cause of emotion stems from interpersonal factors (Miller et al., 2007). In the following chapter I explore how academics manage emotion in their work and highlight the academics personal coping strategies and organisational supports available to academics. 


\section{Chapter 5: Managing emotions of selves and others}

\section{Introduction}

As shown in the previous chapter, academics were often faced with an array of emotions and emotion-inducing situations. This chapter will examine how they would manage the emotions of themselves, and often, of other people as well, in these circumstances. Following this, the chapter will discuss the strategies used by academics to cope with the emotional demands of their roles. It first examines the coping strategies used by academics within the workplace, and then follows on to look at the coping strategies that they use at home. Finally, this chapter examines the organisational support available to academics and makes recommendations as to how the organisation could better support academics.

\section{Surface acting}

Academics would often engage in surface acting when working with their wider colleagues, their management team, or other people at conferences and events. As discussed in the literature review, surface acting is when an individual manages their expressions and behaviour as opposed to their feelings (Hochschild, 1983). The academics in this study engaged in surface acting more when they are put in situations where they do not trust the person they are interacting with, when they have to present a professional face, or when they are in a situation where it is not appropriate to say what they truly feel. Belinda (MCS) explained:

You have to be professional at work and do what is appropriate. You have to be polite to people when you actually just want to strangle them for whatever, for being silly or not doing things they are supposed to, it just has to be how you do things.

They felt that in their role as an academic, people have certain expectations of how they should behave and this influenced how they acted. (Hochschild, 1983) defined emotional labour as "the labor that requires one to induce or suppress feeling in order to sustain the outward countenance that produces the proper state of mind in others" (p. 7) and this is exactly what the academics are doing. They are engaging in emotional labour to regulate their emotions in order to fit the expectations of their work role. Georgia (ECS) explained: 
The role of the academic is to be intelligent, considered, thoughtful, it's not to be a seething mess of emotion [laugh].... So in order to perform ourselves as academics we have to present ourselves on most occasions to others as thoughtful and considered, not as anxiety ridden, even though that is actually probably how we feel most of the time.

Another important aspect in the role of an academic is networking. Christopher (LCS) explained that networking is an important way of building relationships with colleagues, both inside and outside of their university. He noted that building relationships with internal and external colleagues is important for a variety of reasons. The first is support, their colleagues can become their friends "and they become emotionally involved and one can support the other" (Christopher, LCS). The other key reason for networking is to build working relationships with people with whom the academics could collaborate with on professional projects. Often networking is necessary in a professional manner even though the academic personally does not like to engage in it. Adam (ECS) explained:

I'm sitting in conferences or research seminars and I often think to myself "this is absolutely boring, who cares, not important", yet I might compliment the researcher or ask a question that makes out that I am interested.... at conferences you have to network, you have to get to know people, you just have to do it, but often you don't like the people, you can see that they are not like you. I can see that I'm being fake in this scenario... unless you form connections and get out there you won't get on in this job, well I struggle with that.

Francis (LCS) also talked about engaging in surface acting at conferences:

In an academic environment where you're at a conference and somebody's saying something, or speaking and you object to it, or you find it very uncomfortable, or you're angry about it, then you're expected to be able to construct a response to it that will be challenging, but not destructive. 
As these examples show, academics would engage in surface acting in order to meet the professional need to network. They are not necessarily interested in the people they are talking to and they do not try to like them, however they would pretend that they are interested. As Adam (ECS) talked about, when engaging in emotional labour at conferences he struggled with coping with the difference between his actual feelings and how they conflicted with the emotions that he had to display. This is an example of emotional dissonance, which is the internal conflict or discrepancy that "occurs when an employee is required to express emotions which are not genuinely felt in the particular situation" (Zapf, 2002, p. 245). Emotional dissonance has been shown to have negative consequences on employee well-being (Bakker \& Heuven, 2006; Zapf, 2002).

Gender was also an important factor in how academics tried to manage their emotional display. Several of the women interviewed talked about how getting upset at work as a woman could be fatal to their career as they would be seen as not being competent. Building on her earlier comments relating to fulfilling the role of 'the academic', Georgia (ECS) explained:

I pay attention to my breathing, to slow it down, because if you're breathing slowly and calmly, then it's actually really hard to put a heap of anger in your voice, or to sound like you're about to cry... Because to be upset as a woman with a bunch of men is just fatal... I will speak very slowly and deliberately and forcefully and people will be under no illusions about these are the points I am making, and probably detect that what sits below that is a whole bunch of intensity that I'm not going to show them.

Georgia had a previous professional life and drew on this in confronting these situations. She went on to say:

My experience is that women lose credibility with men if they cry at work, so fuck if I am going to give them that chance [laugh]. I will work pretty hard not to cry in front of male superiors in particular, even if what they have said was very distressing, or upsetting. 
These gender examples show how academics are engaging in emotional labour due to display rules. Display rules are defined as the "norms about which emotions members of a social system ought to express" (Rafaeli \& Sutton, 1989, p. 8). These academics would engage in emotional labour in order to show the emotions that they thought were acceptable for their gender to display. Many of the men interviewed felt like it was not appropriate for them to show emotion at work because that is not what a man does. They are meant to be staunch and tough and if they showed emotion then they were showing a weakness. Nevertheless, they also talked about how they would manage their emotional display in order to manipulate a situation to be of benefit to themselves. Some would use humour to seem more approachable, some would consciously start swearing or let certain emotions show in order to make an effect. Evan (MCS) explained:

I ham it up all the time for particular circumstances to get certain effects... To me emotion is a play for you and that includes the bad ones, negative, positive, you can play with them, you can engender them, you can make them work... So I'm exceptionally careful about the terminology I use. I use it for particular effect. I regularly will swear to people to try and put them into a particular position to try and get them feeling a certain way.

This example from Evan (MCS) illustrates deliberate dissonance acting. Evan is acting deliberately in a particular way in order to achieve specific goals for his own purpose, however there are no organisational requirements for him to display these emotions (Van Gelderen et al, 2014; Zapf, 2002).

Academics generally only engaged in surface acting with a student when they needed to manage the emotions of the student. This was typically when a student would feel stressed or frustrated or when they were having other issues in their lives that were affecting their work. Ian (ECS) said:

I need to manage their [students] frustrations and I introduce these theories, and sometimes I really feel tired about that. Because I think it is their responsibility to engage with the readings. 
They would engage in surface acting in these circumstances because often they would sympathise with the student or feel sad for them but they would not want the student to see that. Kate (MCS) said "I want to be seen as the one who has got it all together and is giving the support". This feeling was echoed by other academics as they wanted the student to see them as supportive, knowledgeable and calm.

Extant research argues that engaging in emotional labour can result in negative effects on employees such as absenteeism, depression, substance abuse, diminished self-esteem, and burnout (Grandey, 2000; Hochschild, 1983; Pugliesi, 1999; Rafaeli, 1989; Zapf, 2002). Gimlin (1996) found that emotional labour undermines the worker's sense of professionalism, while others have found that it undermines job satisfaction (Bulan et al., 1997; Parkinson, 1991; Pugliesi \& Shook, 1997). Other negative consequences associated with the performance of emotional labour include dissatisfaction, separation of self and true feelings (Hochschild, 1983), lack of empathy and feeling robotic (Albrechet \& Zemke, 1985), lack of work identity (Van Maanen \& Kunda, 1989), and a lack of openness (Kahn, 1990). Many of these negative consequences were evident with the academics interviewed for this research, as shown in this chapter. All academics employed personally developed coping strategies to help them cope with the emotional demands of their jobs.

\section{Deep acting and genuine acting}

Academics generally felt that when they were teaching they were genuine in their emotions and what they were portraying. As discussed in the literature, genuine acting is when people are able to express the appropriate emotions naturally (Ashforth \& Humphrey, 1993). When teaching it was important for the academics to project enthusiasm and to show excitement for a topic in order to get the students to engage in the material. The academics felt like they did not have to act or 'put on a face' as they genuinely liked, enjoyed, and got excited about teaching. Adam (ECS) explained:

In teaching I do genuinely get excited and want to shake and push students to learn and I enjoy the subject, and people do talk about my passion for the subject in my student evaluations.

However when probed a little more, it became evident that often academics were deep acting. Deep acting is when the individual attempts to genuinely experience the emotion 
that they are outwardly displaying (Hochschild, 1983). Academics would alter their mood, posture and tone of voice before entering a classroom. They did this first and foremost because they enjoy teaching and they want their students to see that. Soon this mood catches on to them and they really feel internally what they are showing on the outside and it is not an effort for them to act excited. Many of the academics do not realise that they are even acting, in this case they feel like they are being genuine. Daniel (LCS) explained:

You have to have a positive emotional energy when you go to teach and sometimes you have to create that.

He went on to say:

When I teach I can bring quite a good spirit to the classroom... I can bring it up, you know "oh geez I have to teach this fucking class again, what is this topic, ah I'm so bored with this, I've been doing it for 10 years [sigh]" that's my thought in the office but then I change, as I walk to the classroom I change how I stand, how I look, I think about what I am doing, I change my emotional representation which I think then really becomes quite internal so then when I am 'acting' in class it becomes much more genuine, because I am creating a positive spirit which is actually reflecting on myself and bringing it out in myself.

Kate (MCS) also acknowledged that sometimes if she has had a hard day then she will have to make an active attempt to really change her mood. Instead of just pretending to be in a positive mood she would attempt to actually make herself feel better because she believes that to get students engaging you have to project genuine excitement when teaching. She said:

"I do physically try and change how I'm feeling".

She later said:

I think face-to-face teaching and even online teaching... it's like being an actor on a stage. If you don't project and show enthusiasm and excitement 
you don't get students engaging. They'll go and do the reading and they'll fill out the exam, but actually get passionate about something and it's what I say to my students. I mean I leap around all over the classroom.

This shows that as well as engaging in deep acting to teach, Kate (MCS) is also trying to manage the emotions of her students and manipulate them to feel the same passion for the topic as she does. As shown above, academics found that as well as managing their own emotions, they were often in situations where they had to manage the emotions of others, particularly students. Students would often come to see the academics with their frustrations and difficulties and expect the academics to provide answers. Often the academic would simply provide a listening ear and this would be enough to calm the student down. This was not necessarily a hard task for them to do, however sometimes the emotions of the other party would spill over onto the academic causing them to also feel sad or frustrated. Georgia (ECS) explained:

I don't want to sit in a room with someone and be immune to what's going on for them... Students get stressed and it's understandable. They want to do well, they're feeling anxious, they're feeling confused, they need help, and sometimes particularly around deadlines, which are a big challenge for them, they're in a very stressed state. So I want them to know that I give a damn, you know in an institutional education model there's got to be some actual people that they feel care for them.

She went on to say:

At some point they will or you can say things that help them calm down and then you can try and help them work through the problem. So it doesn't faze me. I wouldn't say I enjoy it being with people in distress, but I'd rather that they were with someone who gave a damn when they are in distress.

Accounts of positive outcomes of emotional labour appear to be very important in understanding the deep acting and genuine acting described in reference to students. Extant research shows that how the labour is enacted can produce positive outcomes for the employee (Grandey, 2000; Hochschild, 1983; Kruml \& Geddes, 2000; Pugliesi, 1999). 
When employees are in control of their emotion management then they are more likely to experience positive consequences (Pugliesi, 1999). Extant research also shows that employees can feel empowered when they are managing the emotions of others (Leidner, 1993; Stenross \& Kleinman, 1989; Tolich, 1993).

As discussed in the literature review, the effect of career stage has not been examined directly in relation to emotional labour. The majority of previous studies found that when an individual is in the midway stage of their career they had the greatest stress, the least job satisfaction, greatest burnout, most work-family conflict and reported the most negative work setting (Burke, 1989; Cannizzo \& Liu, 1995). The findings from this research did find differences in the causes of emotion between career stages, although due to the nature of this research it cannot be determined which career stage experienced the greatest negative outcomes.

The chapter will now go on to discuss the coping strategies used by academics in the workplace. These coping strategies were employed by academics in order to try and protect their mental well-being, and to try and minimise the negative consequences of emotion work and the performance of emotional labour.

\section{Strategies Used At Work}

It was found that employees used a variety of coping strategies while on the job. Many of these are strategies identified in extant literature as being used across other professions while some appear to be unique to academia. It was found that academics across the career stages have some differences in their coping mechanisms at work. The key strategy used by all academics was to physically remove themselves from the situation and if they could not physically leave then they would mentally remove themselves. Second, academics would seek support from their colleagues. Third, academics would attempt to intellectualise or reframe the situation. Finally, all colleagues would attempt to focus on their work as a coping strategy. A coping strategy which was unique to academics in their mid and late-careers was to say no to work. These will be discussed in the following sections of the chapter. 


\section{Removal}

The key mechanism used by all the academics was to physically remove themselves from a situation at work if it was causing them to get emotional in a way that they did not want. This could occur in a number of ways such as shutting their office door, going outside or having a break somewhere, going to have a coffee, tea or some food, going to the bathroom and sometimes even leaving work early. Belinda (MCS) explained:

At times I have to tell myself not to get involved and not actually enter a situation because I can get very involved in situations. So it's really just to withdraw or close the door to my office and not go out and talk to people because that is probably just the simplest solution. At times I just try to stay out of things, especially things that aren't going to do me any good. There are battles that I can't win.

This method could have serious implications for academics as it appears that many times they will leave or avoid a situation instead of resolving the issue. Adam (ECS) also admitted that because he will avoid conflict situations, it leads to him overthinking them in his mind "and that's something that affects my personal life". He later said that "I'm good at avoiding the situation but I'm not good at avoiding thinking about the situation". Adam (ECS) even admitted that he will purposely use this coping strategy so that he does not have to be the person who will try to resolve the situation. He said:

To be honest the things that are resolved are often more resolved by the other person, so I'm not good at resolving.

The participants in this research articulated strikingly similar attitudes to these types of situations and acknowledged that they will very rarely try to resolve a situation by talking to the other person about it. Therefore, it appears that there may be many issues that go unresolved because academics choose to avoid the situation rather than confront it. This may also have organisational impacts as issues go unresolved, potentially resulting in lower quality work.

Exercise was another way of physically removing themselves from a situation at work. Many academic across the career stages would go in the middle of the day to exercise if 
they needed to try and clear their heads or calm down. Sometimes it could be as simple as running up and down the stairs a few times or going for a walk, while other academics would go for a run or take part in a group exercise class. Evan (MCS) would take part in group fitness martial arts classes and he explained:

Rather than having to go and sit and talk to someone and express your emotions verbally, sometimes expressing them physically is really important, or it works for me. So I'll do that kind of stuff... If I'm feeling like I've had a hard morning I'll go at lunchtime.

Daniel (LCS) also used exercise as a way to help him:

The best thing for me actually is exercise, so I cycle and other exercises too but usually cycling for me. Cycling is absolutely the best thing for calming myself down and giving myself perspective... it's like a miracle.

Adam (ECS) also explained that sometimes he would leave work early if he could not cope with the emotional demands. Sometimes if he had planned to go to the gym in the evening, he would leave and go in the middle of the day instead and then return to work afterwards. He explained that "Sometimes you take off a few hours early coz you're sick of it".

If the academics were in a situation where they were unable to physically leave then they would choose to mentally leave the situation. They would withdraw, disengage from other staff members, or just stop listening. If academics were in a meeting for example, then they would pretend to pay attention but they would think about other things, or they would use that time to plan their day, make to-do-lists. Some academics mentioned that they would take extensive notes and then go and shred them later or discuss them with their colleagues. Ian (ECS) explained how he reacts in meetings when he does not want to listen to what is going on:

I do not listen when they are talking... Oh the meetings are perfect times for planning the rest of the day [laugh], and I make to-do-lists within these meetings. I don't engage with much of the stuff. 
Again, this example shows that academics have many unresolved tensions, which cause withdrawal. This has implications for the organisation as it could result in reduced effectiveness of decision-making.

\title{
Sharing with colleagues
}

Another coping mechanism used by all academics was to talk to their colleagues about their work and what was going on. The colleagues that they shared with were their close colleagues whom they had friendships with, as opposed to just any staff member in proximity. Sharing with their colleagues helped them to discuss similar experiences and know they were not alone in what they were going through, it allowed them to ask for and gain advice. Sometimes they would laugh about the situation together which helped in making the issue seem less important. Francis (LCS) explained:

\begin{abstract}
My close colleagues are all more or less in the same space as I am and we often have sessions where we talk about what's going on and we often share emotional sort of experiences, they become emotionally important. I mean I just co-organised the conference with a colleague... we had a couple of sessions during the conference where we were just having a bit of a catch-up and sort of an emotional unload, given all the pressures that were going on.
\end{abstract}

This coping strategy is beneficial for the employees as they get to feel like they are not alone in what they are going through. With this support the negative emotions they are feeling are supplemented with feelings of happiness, trust and admiration for their fellow colleagues. However, it could be detrimental for the organisation. If the staff are meeting together privately and discussing their negative emotions related to their work and the institution, they could realise that if everybody feels the same way, then they could have the power to do something about it. The potential implications for the organisation in terms of employee commitment are significant.

\section{Intellectualise the situation}

Another coping strategy used by many of the academics was to intellectualise or reframe the situation. This could involve consulting the literature, rationalising what happened, sticking to the facts rather than their emotions, putting things into perspective, for 
example, thinking about the more important things in life like their families, analysing the situation or talking things over in their heads. Georgia (ECS) explained:

When I've experienced major trauma part of my coping mechanism is to need to intellectualise it. So I'll actually go to the research literature and say, okay what does the literature around this tell us?

Some academics would even use what happened and try to turn the emotion into a positive. Some would write about it and they would use what happened as examples in their work. For example, at least one academic was engaged in writing for publication about the PBRF and the detrimental affect it has on academic life and the quality of scholarship. Some academics would acknowledge that the emotion caused by a situation can be used to better understand the situation and some academics realised that emotion could be used to enhance a situation to make it better for themselves. Evan (MCS) explained how when he is involved in an emotional situation he uses those emotions to benefit himself:

You've got to be comfortable with believing that emotion is okay. Getting mad is okay. Crying is okay. Most people are really, well let's try to keep a lid on these emotions during meetings please, you know, that's fucktarditis as far as I'm concerned. Keeping a lid on emotions is fantasising that you're keeping a lid on emotions. Allowing them to be more present is where you're likely to get more change and engagement.

As previously discussed, trying to keep their emotions to themselves can have different implications for men and women. As a man it may be more acceptable in the academic setting for them to show anger, upset and disapproval as they are seen as 'tough'; however for female academics to show these same emotions, they believe they will be seen as 'weak' or 'incompetent'.

\section{Focus on work}

Academics would also focus on work as a coping strategy. They would concentrate on a specific task in order to not have to focus on the emotional situation. If it was a work 
related task such as their research that was causing the emotion then they would switch tasks and do something else. Ian (ECS) explained:

I just focus on my work, I just focus on my own stuff. I try to keep it away, the negative feelings, and I just try to do some good stuff, I'd even write about it, that's how I handle it.

Often academics would find that they could not concentrate on their work and so they would do mundane tasks such as tidying their desk or answering emails. This meant that they were still being somewhat productive but not having to think as much or concentrate on an emotional task. Sometimes tidying their office or desk allowed the academic to feel like they were clearing their mind as well which would enable them to concentrate on their work better. Kate (MCS) explained:

I tidy everything. That corner I hate, but everything gets put away off my desk. I like to have everything off, even if I just open a drawer and shove it all in, I like to come into a clear desk, almost a clear head the next day. So that's one thing I always do.

This coping strategy allowed academics to still continue being productive as it meant that they did not stop working. Due to their high workloads, if they stopped working every time they got emotional then their work would never get completed and it would keep building up, thus adding to their stress.

\section{Saying 'no'}

Finally, a strategy that was unique to mid and late-career academics was their ability to say no and turn down work or opportunities. This allowed them to lessen their workload, avoid over-committing and reducing potential opportunities for stressful or emotional situations to occur. This strategy was not evident for early-career academics as they were still trying to prove themselves as an academic and they did not want people to think badly of them, so they would take up any opportunity that was offered to them. Belinda (MCS) acknowledged that earlier in her career she was not good at saying no to opportunities however as she has progressed through her career she has developed the ability to turn down some opportunities. She explained: 
Academia is rife with people who are quite individualistic and aren't great team players and who just say no to things while other people don't say no to things and end up taking on high workloads. That's not recognised and that can spill over into how you feel about work and I traditionally haven't been very good at saying no to things but I'm probably getting better at it.

Adam (ECS) admitted that he is not good at saying no to work and he often ends up overloading on work:

You could work all the time but get nothing done so the hardest part is to prioritise really, I think it comes down to being able to prioritise and do things efficiently, I'm not good at that yet, that's a skill I have to do better, become more efficient, be able to say no more. Just be able to become more efficient and say no and have a clearer research identity and a smaller teaching load maybe.

The coping mechanism of 'saying no' that has been developed by mid and late-career academics has huge implications for the overall workplace. It actually contributes to the workload, demands, and stresses of the early-career academics. This is because they take on more work projects, and they also feel let down when others do not help them out. This is very important from an institutional viewpoint as it highlights a need for early-career academics to be counselled on 'saying no', but also shows that managers need to address the issue of workload allocation. This issue will be addressed in the conclusion of this research.

Previous studies on coping strategies at work have shown that dominant strategies used are venting or sharing their emotions with colleagues (Bailey \& McCollough, 2000; Hammonds \& Cadge, 2014; Martin, 1999; Williams, 2013), and humour (Martin, 1999; Williams, 2013). In this research, the two dominant strategies used were physically or mentally removing themselves from the situation, and venting or sharing with their colleagues. Humour was only mentioned by one participant in this research; John (ECS) who talked about laughing over situations to make them seem less important. Williams (2013) explained that respondents used humour as a positive coping strategy to deal with difficult situations and move on from them quicker. This was a dominant coping strategy 
in the majority of extant research, and thus it is interesting to note that this did not appear to be so for this research. Other strategies identified in previous studies (Bailey \& McCollough, 2000; Hammonds \& Cadge, 2014; Martin, 1999; Williams, 2013) as ways of coping with their emotional labour which also appeared in this research were reframing situations and avoidance. Unique to this research was the academics coping strategies of focusing on their work, intellectualising a situation and using it as part of their scholarship, and saying no to work.

\section{Strategies Used At Home}

While it was found that academics across the career stages have some differences in their coping mechanisms at work, it was found that they have all developed variations of the same coping strategies for emotion management outside of the workplace. First, all academics have formed social support networks made up of their family and friends, second they engage in a variety of activities to take their minds off work, and finally, while the majority of academics aimed to create a boundary between their work and home lives, it appears that this is impossible, and as a result academics will engage in work-related tasks at home. These strategies will be discussed in the following sections of the chapter.

\section{Social support networks}

The academics interviewed for this research have developed networks of people whom they rely on for emotional support. The primary support person for most academics was their partner/spouse. Most academics would deliberately try to not share their work issues with their parents. Primarily their partners were there to listen and provide support rather than to try and solve the academics work issues. Sometimes academics would use their family or friends to gain perspectives or to help rationalise their problems. When asked about who is her main emotional support person, Georgia (ECS) explained:

My partner especially. He has always been the main person that I'll talk to about work and I do the same for him... So we're each other's support mechanism and actually we generally get enough from each other that we don't need then to bother other people with it and we certainly don't want to bother our parents generally, we don't want them worrying about us, about our jobs because they would. 
She went on to say:

I don't need him to come up with solutions for me. He understands that his job is not to problem solve [laugh]. He's learnt that. But what he does do is, because he's been listening he'll detect a pattern in what I'm saying, which I haven't necessarily been able to articulate myself and he'll feed that back to me, and that's very helpful.

These examples show that purely talking out loud about an issue helps the academic to work through their emotions. They do not necessarily talk to their family to get answers to their problems, particularly as their family would not necessarily understand their work context. The venting was used as a way to excise or conversely ruminate emotions. Some academics chose not to share certain confidential pieces of information, and sometimes academics would choose not to share their issues purely because they knew their partner would not understand the context. Henry (LCS) explained:

Obviously there's a whole sphere of stuff that confidentiality comes into play, so I can't share certain stuff. Other stuff I have to be very circumspect about how I discuss it. Actually one of the things that happens sometimes is I wish I could share and explain to people, but it's often really hard to explain to somebody who is not an academic, who doesn't understand universities, never worked in one, what you're actually talking about. I remember speaking to friends, and they think well why doesn't this happen, why doesn't that happen, and you spend an awful lot of time trying to explain how a university is structured and works. Because they are very peculiar organisations actually.

They're fucking weird.

As this example shows, the network of people that academics can talk to in regards to work issues is actually fairly limited. If they need to talk through the specifics of a problem then that needs to be done with somebody who understands the world of academic, such as their work colleagues. However, their family and friends in their personal lives are useful to just listen to the academics vent. 
Academics also chose to share things with their family and friends as opposed to their work colleagues so that they did not show any weakness to their colleagues. This could potentially make them a target at work and other people could try to take advantage of their weaknesses. Adam (ECS) explained:

Another reason that I talk to people outside is because I never want to show weakness inside to my colleagues. So a driver for me would be if you talk about it, you care about it, so it might get back to that person then they would know that something is annoying you. And the more you talk about it in your area, then they think there is a weakness or you get rattled, whereas it is very important to me how I get perceived, to be professional... The more you let people know about you the more they can characterise your behaviour and what you might do and I don't like that so I stay somewhat private.

As shown, academics feel a need to maintain a positive, professional reputation and this sometimes has implications for whom they can reach out to for help. Academics tend to share their work issues most often with family and friends outside of work. However, they often do not understand the academic context and can therefore usually only offer support and a 'listening ear' as opposed to helping come up with solutions for issues. Their colleagues are the people who actually know and understand the academic context and can therefore be more help to solve a problem or issue, yet academics sometimes chose not to share with their colleagues out of fear of what they might think.

Several academics in their mid and early careers mentioned having young children at home. These academics also mentioned that they have a reasonably well defined work-life balance. They stated that as they had small children who were dependant on them which meant that they often physically could not sit down and do work, and thus they managed to keep their home life quite separate from their work life. Belinda (MCS) explained:

Work is secondary to life. I want to enjoy work but life is more important. I like to get out the door and be home at five o'clock and I want to go and put my kids to bed. 
Daniel, a late-career academic also mentioned that he has a well-defined boundary between his work and home lives. He put this down to having young children when he first started out in academia and so he learnt how to keep his home life separate and he continued this on once his children grew older. Daniel (LCS) explained:

I leave things at the office, I don't let things upset me that much in general and I really leave most of the pressures at the office than at home. I just abate those things fairly well and I always have. It's because when I started my career I had small children and so when I was at the office I could do my work and... unlike some other academics who could go home and do some more work, for me at home there were children running around, it was just mayhem, there was no possible way I was going to do work at home so that's partly why I learned to separate these things.

Daniel (LCS) later went on to say:

I think people should separate work from home. It's easy for a single junior academic to just be working really all the time and I don't think that's healthy, and from my observation in my career, I don't think it's a useful long-term strategy... It's not very sustainable. You need to separate things so that you maintain your health and your emotional stability so that you can continue to be successful.

However it is possible that with the introduction of PBRF in 2003 (Tertiary Education Commission, 2016) the demands facing early-career academics now, are greater than the demands that Daniel (LCS) faced when he was in the early stages of his academic career.

\section{Engaging in activities}

Regardless of the variations in the types of activities academics engaged in, they used activities as a form of distraction to take their minds off work. This was an important part of their emotional management outside of the workplace. Exercise was one of the most important coping strategies used by academics. In addition to exercise as discussed earlier, other activities that academics would take part in fell into two categories. Firstly, activities which took a significant amount of concentration and so the academic would not be able to 
think about work. These were activities such as reading, playing bridge, complex baking and cooking, or reading the news. Kate (MCS) explained:

The more stressed I feel, or the more tense I feel, the more elaborate things I cook, things that take longer to cook. I'll go and buy things that need a whole lot of ingredients and then spend two hours in the kitchen.

She later went on to say:

I play tournament bridge and that will take up a whole day from nine in the morning till seven at night and you can't think about anything else.

These examples seem to show that these coping strategies are aimed at trying to distract themselves and push work issues temporarily out of the academics minds so that they do not take over their personal lives.

Secondly, activities aimed at distracting the academic, but also aimed at relaxing the academic. These were activities such as watching television, going on social media, watching movies, reading trashy books, meditating, going to the beach, or having a drink such as beer, wine or herbal teas. Georgia (ECS) explained:

I'll just blob out in front of the TV, or I'll look at dog-rating on Twitter... It's very funny... Complete nonsense is a really good form of getting away from serious work. A lot of people I follow on Twitter is just complete nonsense, often involving cats and dogs... If I have a really bad day I'm more likely to just drink a lot of herbal tea, rather than go for the wine, because that strikes me as kind of dangerous. But generally if I'm just chilling out I might have a glass of wine. I read fiction, if I've been strung out then it will be trashy fiction, not good fiction and it will be trashy movies, not good movies.

Unlike Georgia (ECS), other academics found having an alcoholic drink after a stressful day was a good coping mechanism to unwind after a hard time at work. John (ECS) explained: 
I probably drink a lot more during the stressful times. Not to the point of alcoholism, but I think you know you definitely have a couple of drinks on a Friday night... I actually definitely think alcohol's a good thing... it's nice to have a drink after work if you're stressed.

Belinda (MCS) admitted that when she was in her twenties and had just started out in academia, she would sometimes go out and join the students for a drink in the evenings. This coping strategy was not unique to any particular career-stage however, and was a coping mechanism used by several people over all the career stages. It is likely that having a drink is more of a personal choice as opposed to a strategy that develops over time. This strategy could even be linked to the wider cultural context of New Zealand, as John (ECS) explained:

Having beers after work, I mean I know it's bad and it's not good for me, but that's the New Zealand thing to do... I tell myself it's okay, because everyone else does it.

Similar to the study by Hammonds and Cadge (2014), engaging in these various activities was used to take their minds away from the emotional strains of their work and "create and maintain emotional boundaries (p. 168), although it is also recognised that there is a danger of not addressing the cause of the issues first.

\section{Keep working}

Finally, the last coping mechanism that academics used at home to cope with the emotional demands of their job was to simply do some work. Although many of the academics suggested that they will try to not take their work home with them, they also acknowledged that this was nearly impossible due to the high workload. Academics found that by completing more mundane work tasks at home such as answering emails, then they were still achieving something and that would be one less task to do at work the next day. Christopher (LCS) explained:

I'll also go and answer emails because every email is from a different person with a different subject and with a different context and requires attention and so that causes me to focus. 
This has implications for stress, as by working at home, the academic does not get a break from work and they continue to focus on the stresses of their work. Previous studies on coping strategies off the job have shown that strategies include socialisation, drinking, partaking in activities, venting or sharing information with family and/or friends and 'calling-in' (Hammonds \& Cadge, 2014; Martin, 1999; Williams, 2013). All of these coping strategies were also used by academics. However, the findings from this research have shown that academics also continue to work from home as a coping strategy. This may differ from studies on occupations such as nursing or policing as academia is individualised and a 'thinking' job which can be carried out from many locations as opposed to an occupation such as nursing where the job must be carried out at a specific location.

The findings show that academics most engage in emotion-focused coping strategies as opposed to problem-focused strategies. Emotion-focused strategies are "cognitive and behavioural efforts directed at reducing or managing emotional distress" (Folkman \& Lazarus, 1980, p. 225). These were strategies such as physical or mental removal from the cause of emotion, exercise and other activities, venting or sharing with colleagues, family or friends, and concentrating on work. Problem-focused strategies are "cognitive problemsolving efforts and behavioural strategies for altering or managing the source of the problem" (Folkman \& Lazarus, 1980, p. 224). Most academics did not try to alter the source of the problem. Occasionally an academic would confront somebody when having an issue with them but this was unusual and typically was not described. With systemic issues, most academics acknowledged that the system was already that way and that they would not be able to change it, and thus they just tried to cope with emotion-focused strategies. Academics in their mid and late-careers did use 'saying no' as a coping strategy and this is an example of a problem-focused strategy as the academics are simply removing the source of the problem before it causes them undue stress or other negative emotions.

This research provides an insight into how academics develop coping strategies over the duration of their career in order to manage their emotions. The mechanisms used by academics are all clear examples of how academics use their coping strategies to try to "protect their own psychological and emotional well-being" (Hammonds \& Cadge, 2014, p. 166). These strategies were largely described as individual and developed 
idiosyncratically in relation to personality and preference. The research also sought to explore the extent to which organisational supports were provided. As discussed below, such supports were limited, and their absence potentially has a greater impact for those newer to academia with less experience.

\section{Organisational support}

Thus far the findings from this research have shown that emotion can be both beneficial and problematic for the organisation. The key questions here therefore are: Is it the organisations responsibility to help their staff to cope with their personal emotions, and if so, what should/could they do? Several participants also questioned whether or not it was the organisations responsibility to help them cope with their emotions. However, many of the stresses that academics are faced with are caused by systemic issues. This section of the chapter examines the academics opinions of their perceived organisational supports. The chapter will then look at the academics personal opinions of organisational support for emotion management.

\section{Perceived organisational supports}

All academics interviewed for this research stated that they have never received any sort of training that was aimed at facilitating their emotion management or related to developing strategies to cope with the emotional demands of their work. Many participants stated that there are training courses available related to managing their workload or relating to teaching lectures, but nothing directly aimed at emotion work. Adam (ECS) stated that there were training courses directed at managing PhD students, and conferences about how to be a good supervisor. He stated that these were very useful as a new academic; however there was nothing directly related to emotion management or the emotional demands of the role.

When asked if there were any resources available to them to help with the emotional demands of their work, some academics mentioned that they can meet with a personal development coach and that there are counselling services available. These counselling services are organised through the employee assistance programme (EAP) and academics are entitled to a certain number of sessions for free. Evan (MCS) and Francis (LCS) had used this service at times when they have been upset about something or struggling with 
their emotions. However other academics felt like this was just another way of getting academics to keep their true feelings away from management. Georgia (ECS) explained:

There's EAP no doubt. Yeah, send us off [laugh]. Send us off to talk about your feelings over there, we don't want to know about it! I think EAP plays an interesting role, but it's a channel for people to go blah blah blah, in order that they don't tell their managers how they're actually feeling because that would be risky.

This shows that there is a tension regarding whether academics really perceive this service as a way of the organisation actually trying to help them. Rather it is the organisation passing the problem onto somebody else so that management does not have to hear about it. As discussed in the research literature, Williams (2013) noted that even with the provision of formal counselling within their organisation, many respondents in her study preferred talking to their colleagues instead as they had personal insights and understandings of the issues. Many academics mentioned that they choose to talk to their colleagues because they had shared experiences. This could be one of the reasons that academics choose to vent or talk to their colleagues instead of using counselling services.

Another resource that was available to new academics was new teacher support meetings. Adam (ECS) found these very useful as "you're in a room with other people who are in the same stage as you for teaching" and it helped him to learn how others teach and their opinions on how to deal with various situations. However, again this was not a programme aimed at helping new academics to develop coping strategies to deal with the emotional demands of their roles.

\section{Academic opinions on training for emotion management and coping strategies}

When asked if they thought that management should implement a training programme aimed at facilitating emotion management and the development of strategies to cope with their emotional demands, the majority of participants answered no. While many of the academics stated that the level of training that they received in this area was inadequate, most participants also said that if there was such training in place that it was highly unlikely they would attend. Ian (ECS) explained: 
I do not believe that people can learn such things with one day or one week training, it's all about implementation of practice. And without really confronting the structural and systemic issues there is no point of having such training. Because there is a very huge material problem there and without acknowledging that, without acknowledging how this creates pressure on people... what's the point of having an emotional training, or training about emotional display.

It is clear that academics do not believe that there is any point in trying to confront their own emotions while the cause of their emotions is not being addressed. Belinda (MCS) was also against the idea of emotion related training. She said:

Personally if something like that was offered... I'd probably say no because I've probably already got a fair idea of what most of it is.

This shows that it appears that once academics are in their mid or late-careers they believe that they have already developed the adequate skills to cope with the emotional demands of their work. However, many academics stated that when they first started out in academia they would take up any training opportunity that was offered to them. Kate (MCS) said that "usually in the first five years of your job is when you tend to go to as much training as you can".

The findings show that most academics are opposed to making any training compulsory, nor did they see the need for training aimed at helping them cope with the emotional demands of their work. As opposed to training, many academics suggested that having a mentor was a better approach to helping themselves cope with the emotional demands of their roles. Evan (MCS) explained:

The best training they [the organisation] can do would be mentoring with other academic staff members, so that you've got a network of people that you can talk to about stuff and you'll learn so much more just from being in those things. 
Kate (MCS) also suggested that having two mentors would be useful in order to get both emotional and administrative or intellectual support. She said:

\begin{abstract}
I would suggest they [the organisation] look at some kind of mentoring or support kind of person, and I would suggest they had two. One that dealt with the emotional social side of the job and one who helped you with promotions and that side of the job. Because they're two very different things. It's very difficult to get a mentor who can do both. And sometimes you want your academic mentor to be in your discipline group, but sometimes you want your social emotional mentor to be the same gender, the same ethnicity, because you often have a connection.
\end{abstract}

As such, mentors would serve to provide both emotional and intellectual support and would be of benefit to academics at all career stages; however it could be a vital difference for early-career academics. Having a mentor could help to guide new academics to learning adequate coping strategies from more experienced individuals. Extant literature shows that mentoring is also important in helping individuals to build confidence and provide reassurance, which, in turn, increases job satisfaction (Williams, 2013). Thus, it is suggested that organisations explore ways in which formal or informal mentoring can be implemented for their employees.

Additionally, organisations could help to mitigate negative emotions in their workplace, and subsequently reduce stress and anxiety by addressing the systemic factors, which cause these negative emotions. The key systemic issues felt by the participants in this research were the pressure to publish and unrealistic expectations. If the organisation can identify ways in which they can minimise these two factors then they may be able to decrease the negative emotions associated with them. There are numerous possible ways how the organisation could do this. For example, they could look at ways in which academics can meet the requirements of the PBRF while still being able to publish and research the things that they want to. The organisation could also look at rewarding academics for aspects of their work other than publications for PBRF. Furthermore, they could look at ways in which they can reduce the workload of the academic staff, leaving them with more time to concentrate on the tasks that they see as being important to their role such as teaching and research. Moreover, this could help to improve the view that 
academic staff have of the management teams and the senior level administrators. The findings showed that many academics had ill-feelings towards these staff members, as they felt that they were giving them extra, unnecessary work that could easily be done by other people. The organisation could also attempt to address a key institutional issue which was felt by many of the participants in this research- fear. Academics felt scared to tell management how they felt and to raise concerns about their working environment. It is important for the institution to explore solutions for these types of systemic issues in order to show their employees that they are cared about, and that their concerns are listened to.

Academics in their early career stage appeared to be the most likely to leave the organisation due to the emotional demands of their work. This is perhaps due to the fact that early career academics have had less time to develop solid coping strategies. The findings also show that academics, across all career stages, would not take up any training opportunities that were offered to them. However, they were most likely to participate in training opportunities in the very early stages of their career. For two reasons, it seems that the organisation could offer emotion management training to new academics. First, this is when academics have not yet developed their own coping strategies, and secondly, this is when academics are most likely to take up training opportunities.

Another reason that early career academics are most likely to leave the organisation could be that they are less institutionalised than the academics in their mid or late careers, and potentially more flexible to take up a variety of opportunities. However, they all enjoyed their jobs, and mentioned that they would only leave if the institutional stresses failed to be minimised.

It was interesting to note, that regardless of the gambit of emotions that academics experienced in their role, when asked if they saw themselves working in the organisation in the next five or ten years the majority of participants answered with a yes. Many of the academics felt privileged and lucky to be working in their role and they really love the work that they do. Daniel (LCS) explained:

I love my job as a whole. Sometimes there are bits of it that frustrate me. But when they frustrate me I sit back and go "well Daniel how can you complain? This is an amazing job, you're so lucky to have it" and I think being an 
academic is a great thing, it's great that we get to work with students, it's fantastic, and I love to do research, I just love it. I love to do the writing, I love to create something and I love to work with other people in this highly intellectual way, so I think we're blessed to be able to work in this profession.

As shown in this chapter, academics engage in emotional labour in order to manage the emotions of themselves and other people. Surface acting was predominantly used when interacting with colleagues and generated negative feelings. Deep acting and genuine acting was predominantly used when interacting with students and generated positive emotions. This chapter then demonstrated the variety of strategies used by academics to cope with the emotional demands of their roles. Within the workplace academics would physically or mentally remove themselves from the situation, seek support from their colleagues, intellectualise or reframe the situation, and/or attempt to focus on their work. Unique to academics in their mid and late-careers was to 'say no' to work. While at home, academics would interact with people from their social support networks made up of their family and friends, engage in a variety of activities, and/or engage in work-related tasks at home. Finally, this chapter examined the organisational support available to academics. In light of the lack of organisational support, several recommendations were made to the organisation relating to ways in which they could attempt to reduce the negative emotions felt by academics. It was recommended that organisations reflect on the broader tertiary education system and pinpoint areas within their organisation where they can reduce the negative consequences resulting from these systemic factors. It was highly recommended the organisations recognise the importance of both intellectual and emotional support, and address ways in which mentoring can be established, particularly for early-career academics. It was also recommended that the organisation implement training programmes for new academics, which are aimed at facilitating emotion management and providing tools to develop adequate strategies to deal with the emotional demands of their roles. 


\section{Chapter 6: Conclusion}

The research question for this study is: What are the emotional demands experienced by academics in the workplace and what strategies do they use to cope with these demands? I also sought to answer a secondary research question: How do these strategies develop and change over the duration of their career? This research revealed that academics experience emotional demands in relation to personal, interpersonal, and systemic factors. As a result, they have developed an array of mechanisms that they use to help them cope with these emotional demands of their work. All academics that were interviewed for this research stated that over the course of their careers they have never received any organisational training aimed at facilitating coping strategies to deal with the emotional demands of their work. As such, each individual has personally developed all their coping strategies over time. There are similarities between each career stage but there are also some notable differences.

As shown in the previous chapters, academics experience a vast array of emotions caused by personal, interpersonal, and systemic factors. All academics have developed coping strategies in order to help them to deal with the emotional demands of their work. The key strategies used at work by academics across all career stages were: physically or mentally removing themselves, intellectualising or reframing the situation, venting or sharing with colleagues, and focusing on their work. Unique to academics in their mid and late careers was saying no to work in order to minimise their workload. At home, all academics engaged in the same coping strategies: having social support networks, engaging in activities, and to keep working. As shown in this research, all coping strategies are used as a way of attempting to minimise harmful effects on their wellbeing.

The lack of adequate coping strategies particularly for early-career academics has serious implications for the academics well-being. All academics felt like their home lives were negatively impacted due to their work and they also felt high levels of stress, anxiety, anger, fear and apprehension when at work. This, in turn, could have serious repercussions for the organisation in terms of employee organisational commitment, job satisfaction, productivity, and burnout. These factors are all highly related as shown in the literature 
review. This research has shown that some academics do take early retirement, or consider leaving the organisation due to stress and other negative emotions.

The academics interviewed did not receive any organisational support in developing adequate coping strategies. Based on these findings it is recommended that institutions focus on developing an understanding of the array of emotions that academics are prone to feel, and the type of coping strategies that academics develop, both on and off the job. This could involve the organisation engaging in processes to discover how they could make academics feel better supported. Institutions could aim to prepare new academics for the emotional demands of their role in academia. The findings from this study show that this could potentially be done through the establishment of a mentoring programme. Through analysis of the findings, recommendations to improving emotional support could be for organisations to implement training programmes for new academics which are aimed at facilitating emotion management and providing tools to develop adequate strategies to deal with the emotional demands of their roles. For their current staff, it is recommended that institutions recognise the systemic pressures that cause negative emotions for academics and explore ways in which they can minimise the negative emotions caused by these systemic factors. It is also recommended that the institution rewards or recognises academics for their scholarly work even when it does not directly contribute to their PBRF ranking. These changes will potentially serve to boost staff morale and mitigate many of the negative emotions felt by academics.

\section{Limitations}

A potential limitation of this research is the sampling method. While snowball sampling is a theoretically sound and widely accepted method, there are also some potential issues. As my research used snowball sampling, I relied completely on the particular people that were recommended to me. As such, the recommended participants were all likely to be colleagues that had close relationships or friendships with the person who recommended them. Consequently, it is possible that the majority of my final participants had similar work ethics, opinions and similar research areas and/or interests. By choosing snowball sampling I have potentially restricted access to other academics with different perspectives. As my research invitation was asking people to talk about their emotions, it could have had the potential to put people off responding. Surprisingly however, the majority of respondents were male. Subsequently, the uneven gender balance may have 
also had a slight impact on the results. I acknowledge this limitation and within the respondents who replied to my invitation to participate in this research I aimed to create the most diverse sample possible through gender, age and tenure.

This small sample of 11 participants from New Zealand business schools is potentially a limitation of this methodology; however, I argue that I am not seeking to find generalizable results. Rather I am aiming to develop insights into in how emotion work is experienced by participants and the methods they have developed in order to cope with this phenomenon.

The timing that the research was conducted could also be of impact to the results. One participant mentioned that because the PBRF is coming up next year then that might have contributed to how academics are experiencing their emotions and their impacts such as stress. For example, if this research was conducted and the PBRF was not occurring for another five years then academics might not feel those institutional pressures as strongly as they are this year. Any potential future changes to policy or legislation could also change people's perspectives. Therefore, it is important to note that this research is a snapshot of time within the academic context. However, the key recommendations remain relevant regardless of timing as discussed earlier in this chapter.

\section{Further research}

These findings have implications for future study of emotion in the academic context, as they show that significant emotion work continues for academics when they leave the workplace. It was shown that the boundaries between home and work life are often blurred and further research could examine the significance that this blurring has on both the individual and the organisation.

From the findings it is highly recommended that future research look at developing theoretical frameworks to study emotion in the workplace. These frameworks should examine emotion as needing to be managed both in the workplace and at home when the institutional environment is the cause of emotion in both settings.

The findings from this study showed that some coping strategies were influenced by home situations such as having young children. Future studies could also aim to explore more in- 
depth, these personal factors. Future studies could also consider the gendered aspect of emotion in the workplace, as was touched on in this research but not explored in great depth.

Further research could also be conducted examining a more diverse sample across different academic disciplines because the emotional content of the academic role may vary. For example the extent to which academics engage with students, need to network, or have a pressure to publish, may vary significantly.

Surprisingly, this research found that the biggest cause of negative emotion came from systemic factors rather than interpersonal relations. Due to the unique findings for the academic context, further exploration could be done around these relationships between academics and the institution. 


\section{Appendices}

\section{Appendix 1: Research Participant Information Sheet}

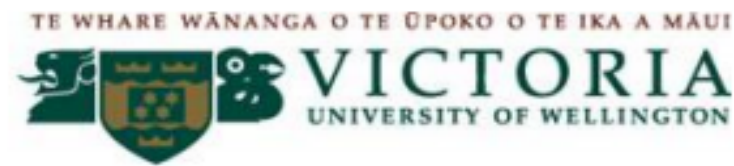

\section{INFORMATION SHEET AND INVITATION TO PARTICIPATE}

\section{Coping with emotion in New Zealand Business Schools}

I am a Masters student in management at Victoria University of Wellington. I am currently undertaking a research project which explores how New Zealand Business School academics experience and cope with the emotional demands of their work. I am particularly interested in how academics have developed coping strategies over their career and the organisational supports that have been made available to them. This research will be used to help inform organisational strategies for staff support.

I would like to invite you to participate in this study. The length of each interview will be 60-90 minutes. Participation is completely voluntary and you may decline to answer questions or terminate the interview at any time. If you wish to withdraw from the research project you may do so without question at any time before $31^{\text {st }}$ March 2016. Data will be securely stored for five years.

\section{Confidentiality}

Within the interview it is important to me that you feel comfortable and that you are able to speak freely. With your permission, interviews will be recorded, transcribed by myself, and cleaned of any identifying information (including real names, organisations or departments) before it is analysed by myself and my supervisor.

As pseudonyms will be used, you will not be named (or personally identified) in the final report. I will use direct quotes to illustrate certain points in the research, but what you say will not be attributed to you personally and anything you say will be presented in a way that cannot identify you.

\section{Where the results will be published}

Two copies of the final thesis will be put on Closed Reserve at the Victoria University library in fulfilment of the Masters requirements. Results of the study may also be published in academic journals.

\section{A summary of the research}

If you are interested in receiving the final results of this study, I can email you a summary of the research after the examination process is completed (this will be after May 2016). There is a space for you to provide your email address on the consent form, or you can contact me at any time.

\section{Who to contact if you have questions}

If you have any questions about the project, please contact me or my supervisor via the contact details below. 
Researcher Contact Information

Supervisor Contact information

\section{Human Ethics Committee information}

This research has been approved by the Victoria University of Wellington Human Ethics Committee. If you have any concerns about the ethical conduct of the research you may contact the Victoria University HEC Convener: Associate Professor Susan Corbett. Email susan.corbett@vuw.ac.nz or telephone +64-4-463 5480. 


\section{Appendix 2: Interview Schedule}

\section{Semi-Structured Interview Guide}

Participants will be welcomed to the interview and advised how the session will run. They will be given the opportunity to read the participant information form and to sign the participant consent form if they have not done so already. The interviewer is willing to answer questions after the participant has read the information sheet. The participant will then fill out the demographic information form before beginning the interview. Participants will be advised that they can answer the questions how they like and they can ask questions or seek clarification at any time. Participants will be aware that they can stop the interview at any time without question. This interview guide is only intended as a guide and questions will be asked in a way that works best with the natural flow of conversation. Some questions may not be necessary for all participants, depending on how they have answered earlier questions.

\section{Warm-up/Career trajectory}

- What is your current role?

- When and where did you begin your academic career?

$>$ Has it been a continuous career?

$>$ If no, why not?

$>$ Did you have any other professional experience before you began to work as an academic?

If yes, can you please elaborate?

- Why did you decide to pursue a career in academia?

\section{General Work Duties}

- Can you please outline what your current role entails?

- Can you tell me about a typical day at your job?

What other activities are you engaged in that do not necessarily occur on a daily basis but are important to the role?

- Who are the main groups of people you work/interact with regularly? (For example. Students, colleagues, industry people etc)

$>$ What different types of relationships do you share with these groups? (For example. collaboration with researchers, authoritative guides for students, advocate for school interests at a faculty level etc)
How do you go about building these relationships?

- Can you please describe the main emotional demands of your role when working with the various groups you mentioned.
Do you experience these demands in relation to managing your own emotions or is it more about managing the emotions of others?

\section{Emotion at work}

- Can you think of a particular time or event when you felt strong emotions when working?

$>$ Can you elaborate what happened?

$>$ How did you deal with it at the time?

$>$ Did this situation continue to affect you once it had been resolved? 
- Do you think that the people have certain expectations of you, and how you should act?

Does this affect how you behave?

- Are all the emotions you display while working genuine in that moment, or do you sometimes have to display emotions that are different to how you actually feel?

$>$ Give details for both yes and no responses

$>$ How does it make you feel when you have to display emotions that are different to what you actually feel?

- Does your emotional connection to a situation sometimes affect your ability to do your job?

$>$ In what ways?

$>$ What do you do if you feel that your ability to do your job is being affected?

- Do you find it difficult to manage the emotions of others in certain situations? (for example, students, other staff)

$>$ How do you deal with this?

$>$ Does this impact on how you act and feel?

- What are the hardest parts of your job?

$>$ What stressors do you experience in your working life?

$>$ Do job stresses affect your personal life?

- What is the most rewarding part of your job?

$>$ How do these positive aspects of your job contribute to your experience of your working life?

\section{Coping Strategies}

- To what extent do you think emotion is an important part of your job?

$>$ To what extent do you think emotion is problematic in your job?

$>$ How do you stop yourself from becoming emotionally involved in a situation?

- If you are involved in an emotionally charged situation, do you do anything while working to calm yourself down?

$>$ What do you do?

- How do you neutralise emotional tensions?

- How do you manage the difference between what you are feeling and what you display?

- If you have had an emotionally charged day, do you do anything to calm yourself down or relax?

$>$ What about when you are on duty/off duty (depending on what they responded with)?

- Do you share your work experiences with family or friends at home or outside of work?

$>$ How?

$>$ Why do you share/not share your experiences?

$>$ Are there some things that you choose not to share?

$>$ Why?

- Who are the main people who support you in managing your emotions?

$>$ How do they help you?

- In what ways do you think your approach to coping with emotional/stressful times draws from your up-bringing or cultural background? 
$>$ What other past experiences have been important in how you have learnt to manage your own emotions and the emotions of others?

- How has your way of dealing with emotionally charged situations changed over time?

Do you deal with situations better now?

\section{Organisational Support and training}

- Did you receive any organisational training to teach you to interact with others?

$>$ If yes, what did this involve?

$>$ What do you think was most important in your training?

$>$ Why?

$>$ Was this training adequate?

$>$ What could be done better?

$>$ Do you still receive training now?

$>$ How does this training differ from your initial training?

$>$ Do you think that this is important?

$>$ Why?

$>$ If no, do you think this should be integrated into the organisation?

$>$ Why?

- Did/does you(r) receive any organisational training to provide you with sufficient knowledge and resources to cope with emotion management?

$>$ What is/was available to you?

- Is there anything that your organisation could do to better support you when dealing with managing your emotions and/or the emotions of others?

$>$ Policies or practices?

- Are there any organisational norms which hinder you dealing with emotional management in a way that you would prefer?

$>$ Could you please elaborate?

\section{Career Duration}

- What advice would you give to a new academic to help them cope with the emotional demands of their work?

$>$ Why is that important?

$>$ Is that something that you knew when you first started?

\section{Summary Questions}

- How do you feel about your job as a whole?

- Do you think you will still be working as an academic in 5-10 years?

$>$ Why/why not?

- Are there any other issues or personal experiences that you would like to add or that you think will be important for this research? 


\section{Appendix 3: Research Participant Consent Form}

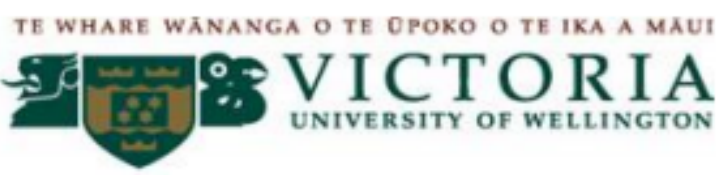

\section{CONSENT TO PARTICIPATE IN RESEARCH}

\section{Coping with emotion in New Zealand Business Schools}

I have read through the attached information sheet and have understood the explanation of this research project. I have had an opportunity to ask questions and have them answered to my satisfaction. I understand that my confidentiality will be assured. I understand that I may withdraw from the research project without question at any time before $31^{\text {st }}$ March 2016 . On this basis I agree to participate in this research.

- I agree to this interview being audio recorded: Yes / No (please circle one)

- I would like to receive a summary of the results of this research when completed.

$$
\text { Yes / No (please circle one) }
$$

If yes, please provide an email address:

Name:

Signature:

Date. 


\section{Appendix 4: Research Participant Demographics Form}

\section{Demographics Form}

1. What is your age?

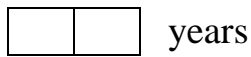

2. How many years have you worked as an academic?

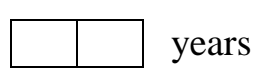

3. How many years have you worked in your current discipline?

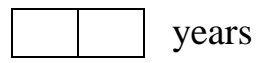

4. What is your job title?

5. Is your work mostly?
a. Teaching
b. Research
c. Administration
d. Other; please specify

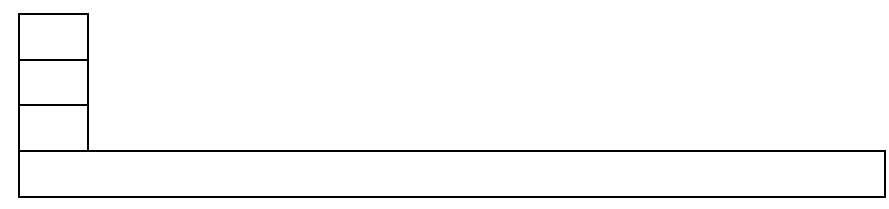

6. What is your highest level of education completed?
a. Bachelor's degree
b. Master's degree
c. $\mathrm{PhD}$ degree
d. Other; please specify

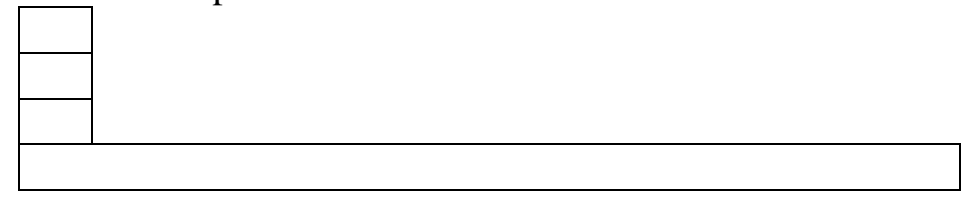

7. What is your race/ethnicity?
a. New Zealand
European
b. Maori
c. Pacific Island
d. Asian
e. Other European; please specify
f. Other; please specify

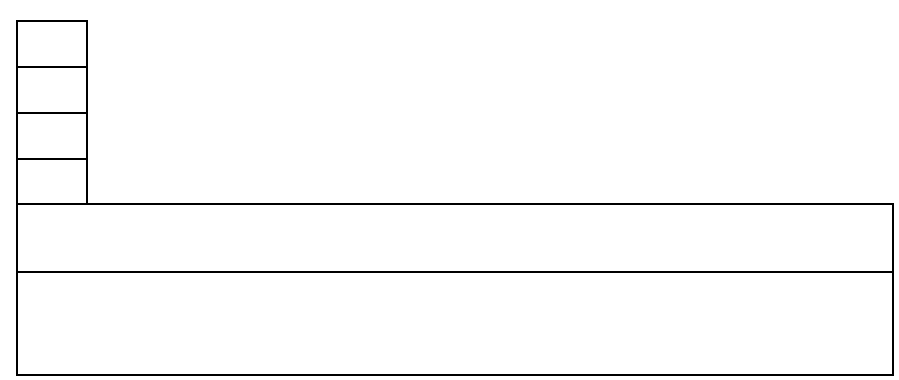

8. Do you have any family members in academia?

If Yes; please state

$$
\begin{aligned}
\text { No } & \square \\
\text { Yes } &
\end{aligned}
$$
relation to you 
9. What is your marital status?
a. Single
b. Married
c. Other

Adapted from (Burke, 1989) 


\section{References}

Abraham, R. (1998). Emotional dissonance in organizations: antecedents, consequences and moderators. Genetic, Social, and General Psychology Monographs, 124, 229-246.

Adelmann, P. K. (1995). Emotional labor as a potential source of job stress. In S. L. Sauter, \& L. R. Murphey (Eds.), Organizational risk factors for job stress (pp. 371-381). Washington, DC: American Psychological Association.

Adkins, L. (1995). Gendered work: Sexuality, family and the labour market. Buckingham: Open University Press.

Albrechet, K., \& Zemke, R. (1985). Service America! Doing business in the new economy. Homewood, IL: Dow Jones-Irwin.

Alvesson, M., \& Skoldberg, K. (2009). Reflexive methodology: New vistas for qualitative research. London, England: Sage.

Arthur, M. B., Hall, T., \& Lawrence, B. S. (1989). Handbook of career theory. New York: Cambridge University Press.

Arvey, R. D., Renz, G. K., Watson, T. W. (1998). Emotionality and job performance: implications for personnel selection. Research in Personnel and Human Resources Management, 16, 103-147.

Ashforth, B, E. (2000). Foreward. In Ashkanasy, N.M., Härtel, C.E.J. \& Zerbe, W.J.,eds. Emotions in the Workplace: Research, Theory, and Practice. Westport: Quorum Books. pp. xi-xii.

Ashforth, B. E., \& Humphrey, R. H. (1993). Emotional labor in service roles: The influence of identity. Academy of Management Review, 18(1), 88-115. 
Ashforth, B. E., \& Mael, F. (1989). Social identity theory and the organization. Academy of Management Review, 14, 20-39.

Babbie, E. (1995). The practice of social research. Belmont, CA: Wadsworth.

Bailey, J. J., \& McCollough, M. A. (2000). Emotional labor and the difficult customer: Coping strategies of service agents and organizational consequences. Journal of Professional Services Marketing, 20(2), 51-72.

Bakker, A. B., \& Heuven, E. (2006). Emotional dissonance, burnout, and in-role performance among nurses and police officers. International Journal of Stress Management, 13(4), 423-440.

Baldwin, R. G. (1990). Faculty career stages and implications for professional development. In J. Schuster \& D. Wheeler (Eds), Enhancing faculty careers (pp. 20-40). San Francisco: Jossey-Bass.

Bayer, A. E., \& Dutton, J. E. (1977). Career age and research- Professional activities of academic scientists. Journal of Higher Education, 48 (May/June), 259-282.

Beck, K., \& Wilson, C. (2001). Have we studied, should we study, and can we study the development of commitment? Methodological issues and the development study of work-related commitment. Human Resource Management Review, 11, 257-278.

Bellas, M. L. (1999). Emotional labor in academia: the case of professors. Annals of the American Academy of Political and Social Science, 561, 96-110.

Bischof, G. H., Warnaar, B. L., Barajas, M. S., \& Dhaliwal, H. K. (2011). Thematic analysis of the experiences of wives who stay with husbands who transition male-to-female. Michigan Family Review, 15(1), 16-34. 
Blackburn, R. T. (1972). Tenure: Aspects of job security on the changing campus. Research monograph 19. Atlanta: Southern Regional Education Board.

Blackburn, R. T., Behymer, C. E., \& Hall, D. E. (1978). Research note: Correlates of faculty publications. Sociology of Education, 51(April), 132-141.

Braun, V., \& Clarke, V. (2006). Using thematic analysis in psychology. Qualitative Research in Psychology, 3, 77-101.

Briner, R. B. (1995). Emotional dissonance, emotional deviance, true feelings, and the self in organizational life. Paper prepared for the $12^{\text {th }}$ EGOS Colloquium, 6-8 July (Istanbul, Turkey).

Briner, R. B. (1999). The neglect and importance of emotion at work. European Journal of Work and Organizational Psychology, 8, 323-346.

Brooks, J. L., \& Seers, A. (1991). Predictors of organizational commitment: Variations across career stages. Journal of Vocational Behaviour, 38, 53-64.

Brotheridge, C. M., \& Lee, R. T. (1998). On the dimensionality of emotional labor: development and validation of an emotional labor scale. Paper presented at the $1^{\text {st }}$ Conference on Emotions in Organizational Life, 7.-8.8.98, San Diego, CA.

Bryman, A., \& Bell, E. (2011). Business research methods, New York: Oxford University Press.

Bulan, H. F., Erickson, R. J., \& Wharton, A. S. (1997). Doing for others on the job: The affective structure of service work. Social Problems, 44, 235-256.

Burke, R, J. (1989). Career stages, satisfaction, and well-being among police officers. Psychological Reports, 65, 3-12.

Burr, V. (2003). Social Constructionism. New York: Psychology Press. 
Büssing, A., \& Glaser, J. (1999). Interaktionsarbeit. Konzept und Methode der Erfassung im Krankenhaus [Interaction work. Concept and measurement methods in hospitals]. Zeitschrift fur Arbeitswissenschaft, 53, 164-173.

Cannizzo, T. A., \& Liu, P. (1995). The relationship between levels of perceived burnout and career stage among sworn police officers. Police Studies, 18(3-4), 53-68.

Chodorow, N. (1980). The reproduction of mothering. Berkeley: University of California Press.

Constanti, P., \& Gibbs, P. (2004). Higher education teachers and emotional labour. The International Journal of Educational Management, 18(4/5), 243-249.

Corbin, M. (1971). Appendix 3. In J. M. Pahl \& R. E. Pahl, Managers and their wives. London: Allen Lane.

Cricco-Lizza, R. (2014). The need to nurse the nurse: Emotional labor in neonatal intensive care. Qualitative Health Research, 24(5), 615-628.

Cytrynbaum, S., \& Crites, J. (1989). The utility of adult development theory in understanding the career adjustment process. In M. Arthur et al. (Eds), Handbook of career theory (pp. 11-21). Cambridge: Cambridge University Press.

Cytrynbaum, S., Lee, S., \& Wadner, D. (1982). Faculty development through the life course. Journal of Institutional Development, 5, 11-21.

Denzin, N. K., \& Lincoln, Y. S. (2011). The Sage Handbook of Qualitative Research (eds). Thousand Oaks, CA: Sage. 
DiCicco-Bloom, B., \& Crabtree, B. F. (2006). The qualitative research interview. Medical Education, 40, 314-321.

Diefendorff, J. M., \& Gosserand, R. H. (2003). Understanding the emotional labor process: a control theory perspective. Journal of Organizational Behavior, 24, 945-959.

Domagalski, T. (1999). Emotion in organizations: Main currents. Human Relations, $52,833-852$.

Dowd, K. O., \& Kaplan, D. M. (2005). The career life of academics: Boundaried or boundaryless? Human Relations, 58(6), 699-721.

Ekman, P. (1973). Cross culture studies of facial expression. In P. Ekman (Ed.), Darwin and facial expression: A century of research in review (pp. 169-222). New York: Academic Press.

Fisher, C. D., \& Ashkanasy, N. M., (2000). The emerging role of emotions in work life; an introduction. Journal of Organizational Behavior, 21, 123-129.

Folkman, S., \& Lazarus, R. S. (1980). An analysis of coping in a middle-aged community sample. Journal of Health and Social Behaviour, 21(3), 219-239.

Fulton, O., \& Trow, M. (1974). Research activity in higher education. Sociology of Education, 47(winter), 29-73.

Gimlin, D. (1996). Pamela's place: Power and negotiation in the hair salon. Gender \& Society, 10, 505-526.

Goffman, E. (1959). The presentation of self in everyday life. New York: Doubleday Anchor. 
Grandey, A. A. (1998). Emotional labor: a concept and its correlates. Paper presented at the $1^{\text {st }}$ Conference on Emotions in Organizational Life, 7.-8.8.98, San Diego, CA.

Grandey, A. A. (2000). Emotion regulation in the workplace: A new way to conceptualize emotional labor. Journal of Occupational Health Psychology, 5, 95-110.

Greenhaus, J. H., Callanan, G. A., \& Godshalk, V. M. (2000). Career management $\left(3^{\text {rd }}\right.$ ed.). Fort Worht, TX: Dryden Press.

Guba, E. G., \& Lincoln, Y. S. (1994). Competing paradigms in qualitative research. In N. K. Denzin \& Y. S. Lincoln (Eds.), Handbook of qualitative research (pp. 105-117). Thousand Oaks, CA: Sage.

Guba, E. G., \& Lincoln, Y. S. (1985). Naturalistic inquiry. Newbury Park, CA: Sage.

Hammonds, C., \& Cadge, W. (2014). Strategies of emotion management: not just on, but off the job. Nursing Inquiry, 21(2), 162-170.

Hannabus, S. (1996). Research interviews. New Library World, 97(5), 22-30.

Herzberg, F. (1976). The managerial choice: To be efficient and to be human. Homewood, IL: Dow Jones-Irwin.

Herzberg, F., Mausner, B., \& Snyder, B. S. (1959). The motivation to work. New York: John Wiley.

Hochschild, A. R. (1979). Emotion work, feeling rules, and social structure. American Journal of Sociology, 85, 551-575.

Hochschild, A. R., (1983). The Managed Heart: Commercialization of Human Feeling. Berkeley, CA: University of California Press. 
Holland, J. L. (1973). Making vocational choices: A theory of careers. Englewood Cliffs, NJ: Prentice Hall.

Hyde, K. F. (2000). Recognising deductive processes in qualitative research. Qualitative Market Research, 3(2), 82-90.

Jenkins, S., \& Conley, H. (2005). Emotional labour in the teaching profession. Management Research News, 28(9), 67-68.

Kahn, W. A. (1990). Psychological conditions of personal engagement and disengagement at work. Academy of Management Journal, 33, 692-724.

Karabanow, J. (1999). When caring is not enough: Emotional labor and youth shelter workers. Social Service Review, 340-357.

Kaur, K., \& Sandhu, H. S. (2010). Career stage effect on organisational commitment: Empirical evidence from Indian banking industry. International Journal of Business and Management, 5(12), 141-152.

Kruml, S. M., \& Geddes, D. (1998). Catching fire without burning out: is there an ideal way to perform emotional labor? Paper presented at the $1^{\text {st }}$ Conference on Emotions in Organizational Life, 7.-8.8.98, San Diego, CA.

Kruml, S. M., \& Geddes, D. (2000). Exploring the dimensions of emotional labour: The heart of Hochschild's work. Management Communication Quarterly, 14(1), $8-49$.

Ladd, E. C., \& Lipset, S. M. (1975). The divided academy: Professors and politics. New York: McGraw-Hill.

Larner, W., \& Le Heron, R. (2005). Neo-liberalizing spaces and subjectivities: reinventing New Zealand universities. Organization, 12(6), 843-862. 
Lazarus, R. S. (1979). Positive denial: The case for not facing reality. Psychology Today, 13(6), 47-60.

Leidner, R. (1993). Fast food, fast talk: Service work and the routinization of everyday life. Berkeley: University of California Press.

Levinson, D. J. (1986). A conception of adult development. American Psychologist, 41, 3-13.

Levinson, D. J., Darrow, C. N., Klein, E. B., Levinson, M. H., \& Mckee, B. (1978). The season of man's life. New York: Alfred A. Knopf.

Lord, R. G., Klimoski, R., \& Kanfer, R. (2002). Emotions in the workplace. San Francisco: Jossey-Bass.

Mack, N., Woodsong, C., MacQueen, K. M., Guest, G., Namey, E. (2005). Qualitative Research Methods: A data collector's field guide. North Carolina: Family Health International.

Mann, S. (1999). Emotion at work: to what extent are we expressing, suppressing, or faking it? European Journal of Work and Organizational Psychology, 8, 347369.

Mann, S. (1997). Emotional labour in organizations. Leadership \& Organization Development, 18(1), 4-12.

Mann, S. (2005). A health-care model of emotional labour: An evaluation of the literature and development of a model. Journal of Health Organization and Management. 19(4/5), 304-317.

Martin, S. E. (1999). Police force or police service? Gender and emotional labour. Annals of the American Academy of Political and Social Science, 561, 111-126. 
McElroy, J, C., Morrow, P. C., \& Wardlow, T. R. (1999). A career stage analysis of police officer work commitment. Journal of Criminal Justice, 27(6), 507-516.

McKinney, K. (1988). Faces: Five components of quality teaching. Teaching Sociology, 16(3), 298-301.

Meares, M. M., Oetzel, J. G., Torres, A., Derkacs, D., \& Ginossar, t. (2004). Employee mistreatment and muted voices in the culturally diverse workplace. Journal of Applied Communication Research, 32, 4-27.

Miller, K. (2002). The experience of emotion in the workplace; Professing in the midst of tragedy. Management Communication Quarterly, 15(4), 571-600.

Miller, K. I, Considine, J., \& Garner, J. (2007). "Let me tell you about my job". Exploring the terrain of emotion in the workplace. Management Communication Quarterly, 20(3), 231-260.

Miller, K. I., Ellis, B. H., Zook, E. G., \& Lyles, J. S. (1990). An integrated model of communication, stress, and burnout in the workplace. Communication Research, 17, 300-326.

Mobley, W. H., Griffeth, R. H., Hand, H. H., \& Meglino, B. M. (1979). Review and conceptual analysis of the employee turnover process. Psychological Bulletin, $86(2), 493-522$.

Morris, J. A., \& Feldman, D. C. (1996). The dimensions, antecedents, and consequences of emotional labor. The Academy of Management Review, 21(4), 986-1010.

Morris, J. A., \& Feldman, D. C. (1997). Managing emotions in the workplace. Journal of Managerial Issues, 9, 257-274. 
Mowday, R., Porter, L. W., \& Steer, R. M. (1982). Employee-organization linkages: The psychology of commitment, absenteeism and turnover. San Diego, CA: Academic Press.

Nerdinger, F. W., \& Röper, M. (1999). Emotionale Dissonanz und Burnout. Eine empirische Untersuchung im Pflegebereich eines Universitätskrankenhauses [Emotional dissonance and burnout. An empirical examination in the nursing sector of a university hospital]. Zeitschrift für Arbeitswissenschaft, 53, 187-193.

Ogbonna, E., \& Harris, L. C. (2004). Work intensification and emotional labour among UK university lecturers: An exploratory study. Organization Studies, 25(7), 1185-1203.

O'Leary, Z. (2014). The essential guide to doing your research project. London: Sage Publications Ltd.

Ornstein, S., Cron, W. L., \& Slocum, J. W. (1989). Life stages versus career stage: A comparative test of the theories of Levinson and Super. Journal of Organizational Behaviour, 10, 117-133.

Parke, A. (1993). Messy research, methodological predispositions, and theory development in international joint ventures. Academy of Management Review, $18(2), 227-268$.

Parkinson, B. (1991). Emotional stylists: Strategies of expressive management among trainee hairdressers. Cognition and Emotion, 5, 419-434.

Patton, M. Q. (1990). Qualitative evaluation and research methods (2 ${ }^{\text {nd }}$ ed.). Newbury Park, CA and London: Sage.

Pelz, D. C., \& Andrews, F. M. (1976). Scientists in organizations. Revised Edition. New York: Wiley. 
Pugliesi, K., \& Shook, S. L. (1997). Gender, jobs, and emotional labor in a complex organization. In R. J. Erikson \& B. Cuthbertson-Johnson (Eds), Social perspectives on emotion (vol. 4, pp. 283-316). New York: JAI.

Pugliesi, K. (1999). The consequences of emotional labor: effects on work stress, job satisfaction, and well-being. Motivation and Emotion, 23(2), 125-154.

Rafaeli, A. (1989). When cashiers meet customers: An analysis of the role of supermarket cashiers. Academy of Management Journal, 32, 245-273.

Rafaeli, A., \& Sutton, R. (1989). The expression of emotion in organizational life. In L. L. Cummings \& B. M. Staw (Eds.), Research in organizational behaviour (pp. 1-42), vol 11. Greenwich, CT: JAI Press.

Ray, E. B. (1987). Supportive relationships and occupational stress in the workplace. In T.L. Albrecht \& M. B. Adelman (Eds.), Communicating social support (pp. 172-191). Beverly Hills, CA: Sage.

Reichers, A. E. (1986). Conflict and organizational commitment. Journal of Applied Psychology, 71, 508-514.

Sabharwal, M. (2013). Comparing research productivity across research disciplines and career stages. Journal of Comparative Policy Analysis: Research and Practice, 15(2), 141-163.

Sawbridge, Y., \& Hewison, A. (2013). Thinking about the emotional labour of nursing - supporting the nurses to care. Journal of Health Organization and Management, 27(1), 127-133.

Scherer, K. R. (1997). Emotion. In W. Stroebe, M. Hewstone, \& G. M. Stephenson (Eds.), Sozialpsychologie. Eine Einführung ( $3^{\text {rd }}$ ed.) (pp. 293-330). Berlin: Springer. 
Schmisseur, A. (2003). The art of well-being: Managing emotional dissonance in the workplace. Paper presented at the International Communication Association annual meeting, San Diego: CA.

Schuster, J. H., \& Wheeler, D. W. (1990). Enhancing faculty careers: Strategies for development and renewal (Eds). San Francisco: Jossey-Bass.

Seldin, P. (1980). Successful faculty evaluation programmes: A practical guide to improve faculty performance and promotion/tenure decisions. Crugers, NY: Coventry Press.

Sharpe, E. K. (2005). "Going above and beyond": The emotional labor of adventure guides. Journal of Leisure Research, 31(1), 29-50.

Stenross, B., \& Kleinman, S. (1989). The highs and lows of emotional labor: Detectives' encounters with criminals and victims. Journal of Contemporary Ethnography, 17(4), 435-452.

Stern, G. G. (1970). People in context: Measuring person-environment congruence in education and industry. New York: John Wiley.

Sundstrom, E. (1986). Work places: The psychology of the physical environment in offices and factories. Cambridge, England: Cambridge University Press.

Super, D. (1957). The psychology of careers. New York: Harper.

Sutten, R. I., \& Rafaeli, A. (1988). Untangling the relationship between displayed emotions and organizational sales: The case of convenience stores. Academy of Management Journal, 31(3), 461-487.

Tajfel, H., \& Turner, J. C. (1985). The social identity theory of intergroup behaviour. In S. Worchel \& W. G. Austin (Eds.), Psychology of intergroup relations $\left(2^{\text {nd }}\right.$ ed.) (pp. 7-24). Chicago: Nelson-Hall. 
Tertiary Education Commission. (2016). Performance-based research Fund. Retrieved from http://www.tec.govt.nz/Funding/Fund-finder/PerformanceBased-Research-Fund-PBRF-/

Thompson, R. K. (1971). How does the faculty spend its time? Mimeographed. Seattle: University of Washington.

Tolich, M. B. (1993). Alienating and liberating emotions at work: Supermarket clerks' performance of customer service. Journal of Contemporary Ethnography, 22, 361-381.

Tracy, S. J., and Tracy, K. (1998). Emotion labor at 911: A case study and theoretical critique. Journal of Applied Communication Research, 26, 390-411.

Van Gelderen, B. R., Bakker, A. B., Konijn, E. A., \& Binnewies, C. (2014). Daily deliberate dissonance acting among police officers. Journal of Managerial Psychology, 29(7), 884-900.

Van Maanen, J., \& Kunda, G. (1989). "Real feelings": Emotional expression and organizational culture. In B. Staw and L. L. Cummings (Eds.), Research in organizational behaviour, Vol 11 (pp. 43-103). Greenwich, CT: JAI Press.

Van Manen, M. (1997). From meaning to method. Qualitative Health Research, 7(3), 345-369.

Vitaliano, P. P., Russo, J., Carr, J. E., Maiuro, R. D., \& Becker, J. (1985). The ways of coping checklist: Revision and psychometric properties. Multivariate Behavioural Research, 20, 3-26.

Waldron, V. R. (2000). Relational experiences and emotion at work. In S. Fineman (Ed.), Emotion in organizations ( $2^{\text {nd }}$ ed.; pp. 64-82). London: Sage. 
Waring, M. (2013). All in this together? HRM and the individualisation of the academic worker. Higher Education Policy, 26, 397-419.

Wharton, A. S. (1993). The affective consequences of service work: Managing emotions on the job. Work and Occupations, 20, 205-232.

Wharton, A. S. (1996). Service with a smile: Understanding the consequences of emotional labor. In C. L. MacDonald \& C. Sirianni (Eds.), Working in the service society (pp. 91-112). Philadelphia: Temple University Press.

Williams, A. (2013). The strategies used to deal with emotion work in student paramedic practice. Nurse Education in Practice, 13, 207-212.

Willmott, H. (1995). Managing the academics: Commodification and control in the development of university education in the U.K. Human Relations, 48(9), 9931027.

Winograd, K. (2005). Good day, bad day: Teaching as a high-wire act. Lanham, MD: Scarecrow Education

Zapf, D. (2002). Emotion work and psychological well-being: A review of the literature and some conceptual considerations. Human Resource Management Review, 12, 237-268.

Zhang, Q., \& Zhu, W. (2008). Exploring emotion in teaching: Emotional labor, burnout, and satisfaction in Chinese higher education. Communication Education, 57(1), 105-122. 